\title{
Construyendo comunidades de aprendizaje
}

\author{
programa de \\ formación de educadoras \\ de niñas y niños de 0 a 6 años
}

\section{Estrategias \\ de \\ Vinculación} entre la Familia

\section{Yla Escuela}

Rosa María Nashiki Angulo

Roxanna Pastor Fasquelle

Miguel Ángel Pérez Figueroa

Rocío Hernández Mares

Leticia Lemus Romo

Carla Ocón Padilla

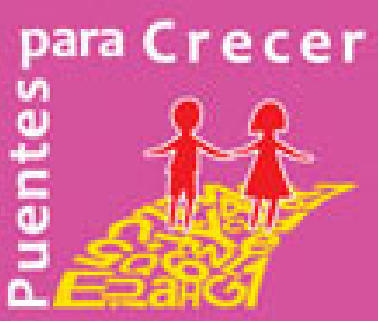




\section{Puentes para Crecer}

Responsable: Dra. Ileana Seda Santana

Coordinadora general: Dra. Nidia Flores Montañez

Coordinadora administrativa: C. Macaria Ofelia Sánchez Cuello

Puentes para Crecer tiene como objetivo incidir en el desarrollo, cuidado y bienestar de niños y niñas en la primera infancia, ofrece apoyos a cuatro comunidades urbano populares a través de los siguientes subprogramas:

Promoción de habilidades de comunicación social en niños preescolares

Responsable: Dra. Lizbeth Vega Pérez

Programa de Formación de Educadoras

Responsable: Mtra. Roxanna Pastor Fasquelle

Formando Lazos en la Comunidad Escolar

Responsables: Mtro. Andrés Díaz Baños

Dra. Nidia Flores Montañez

Dra. Iliana Guadalupe Ramos Prado

La sala de los Libros Mágicos

Responsable: Dra. Ileana Seda Santana

Mamás y Papás en acción

Responsable: Lic. Roberta L. Flores Ángeles

Puentes para crecer agradece el apoyo de:

- La Fundación Bernard van Leer de la Haya, Holanda, por los fondos donados a la Facultad de Psicología de la UNAM para el desarrollo del mismo.

- La Facultad de Psicología de la UNAM, por su contribución de personal académico, infraestructura y en la administración de los fondos.

- El Dr. Javier Nieto Gutiérrez director la Facultad de Psicología.

- La Dra. Lucy María Reidl Martínez quien durante su gestión como directora de la Facultad de Psicología apoyó el inicio de este programa.

- Los espacios educativos y de servicio que fueron sede de los sub-programas.

Diseño de Portada: Mayrení Senior Seda

Revisión de Estilo: Cecilia Fernández Zayas

Responsable de Edición: Ma. Elena Gómez Rosales 


\section{construyendo Comunidades de Aprendizaje}

un Programa de Formación

de Educadorass de Niñosy $y$ Niños de 0 a 6 Años

Estrategias de vinulación entre

la Familia y la Escuela
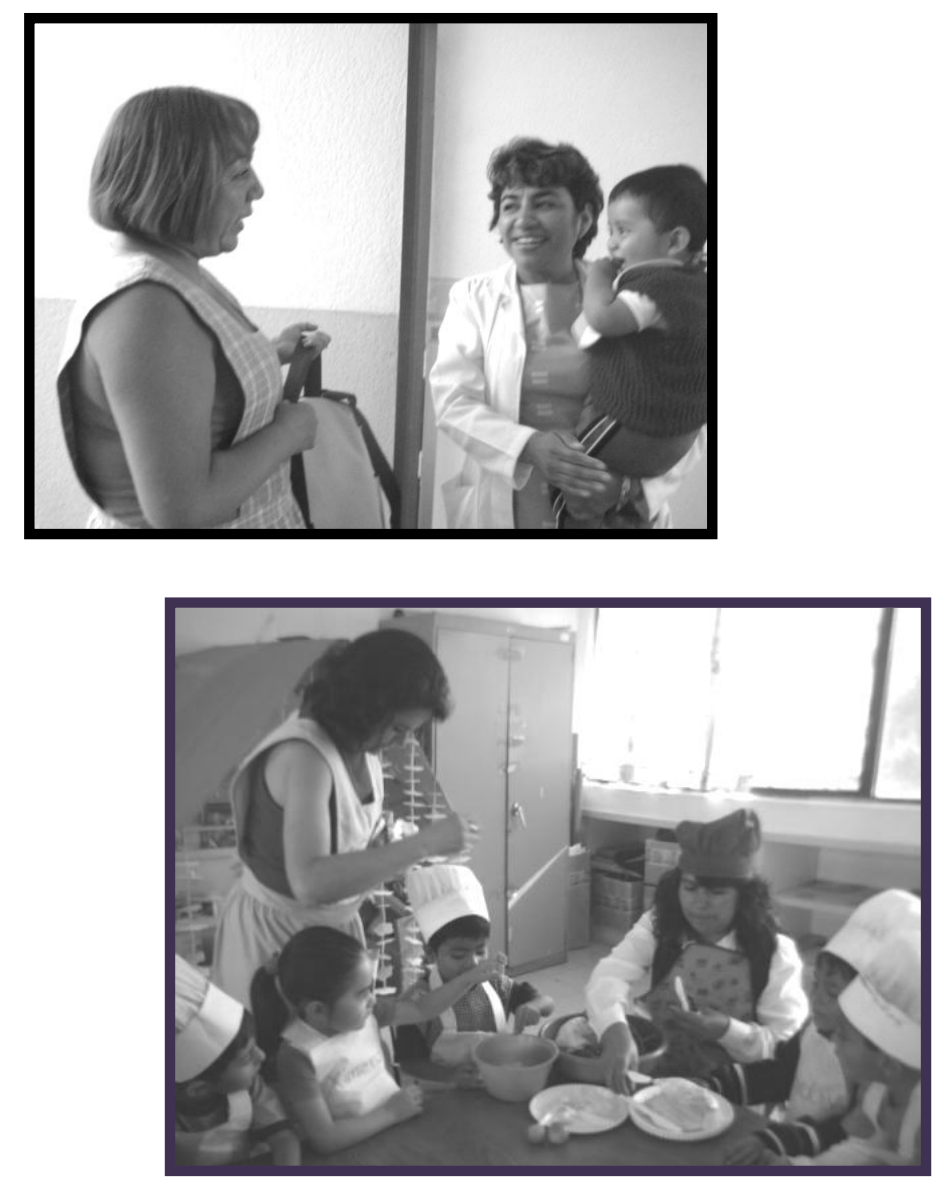

Rosa María Nashiki Angulo

Roxanna Pastor Fasquelle

Miguel Ángel Pérez Figueroa

Rocío Hernández Mares

Leticia Lemus Romo

Carla Ocón Padilla 
Presentación

Introducción

4

Encuentros personales

9

Encuentros espontáneos 10

Juntas informativas

Visitas al salón 12

Proyectos de trabajo 13

Entrevistas 15

Pláticas 18

Talleres 19

Visitas domiciliarias 20

Materiales impresos 21

Trípticos 22

Hojas de información básica 23

Carteles 24

Murales 25

Mensajes 27

Buzón 28

Diario 29

Circulares informativas 30

Evaluación de las estrategias empleadas 31

Bibliografía 33

Anexos 35

\section{$-2-$}

Construyendo Comunidades de Aprendizaje: Un Programa de Formación de Educadoras de niños y niñas de o a 6 años. Estrategias de vinculación entre la Familia y la Escuela. Rosa Nashiki, Roxanna Pastor, Miguel Pérez, Rocío Hernández, Leticia Lemus y Carla Ocón. 


\section{Presentación}

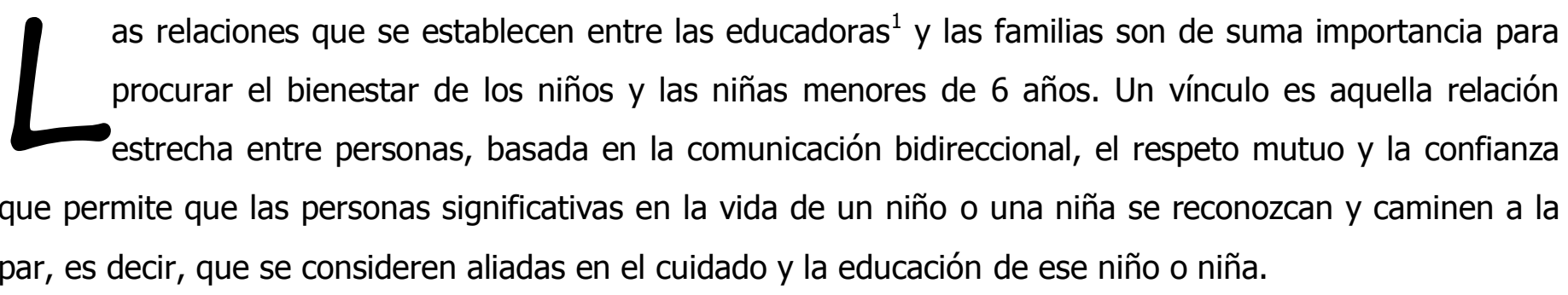

Este material fue elaborado pensando en apoyar a las educadoras de cualquier centro educativo que trabajan con niñas y niños menores de 6 años y sus familias. En él compartimos algunas estrategias que favorecen el establecimiento de relaciones colaborativas entre las familias y la escuela.

Algunas de estas estrategias pueden implementarse casi de forma inmediata para abrir y mantener la comunicación con las familias, mientras que otras requieren de cierto grado de preparación y pueden utilizarse para dar información específica acerca del proceso de desarrollo de las niñas y los niños, así como para desarrollar proyectos conjuntos.

Te recomendamos leer cada una detenidamente, pensar en aquello que deseas lograr con las familias con las que trabajas, tener en mente las características de las niñas y los niños de tu grupo, y una vez considerado todo lo anterior, decidir cuál es la estrategia más apropiada.

Esperamos que este texto te sea de utilidad.

\footnotetext{
1 En este proyecto se reconoce y valora la labor de las educadoras, como un agente educativo que desea trabajar con familias. Durante el documento se utiliza el concepto educadora para hacer referencia a todo profesional que desee trabajar con familias
} 


\section{Introducción}

E México la Secretaría de Educación Pública ha establecido que la educación inicial y preescolar requiere de la colaboración entre la escuela y las madres/padres de familia; para que esta colaboración sea posible deben existir propósitos comunes, y para ello es indispensable promover una estrecha comunicación entre ellos, es decir, escuchar las opiniones de los padres/madres de familia sobre los avances que identifican en sus hijos/as y así como las opiniones que éstos externan en su casa respecto del trabajo que realizan con su maestra o sus impresiones de lo que observan que sucede en el centro educativo (García-Bacede, 2003; SEP, 2004).

Además de lo anterior, autores como Abrego-Sánchez y Martínez-Luna (2005), y Cataldo (1991), afirman que durante los primeros años de la vida y escolarización del niño/a, las interacciones entre las personas que les enseñan y cuidan son muy importantes para ellos y ellas. En el caso de los niños y las niñas menores de 6 años, las educadoras y las personas con quienes conviven día con día son precisamente las más significativas. Cuando estas personas logran comunicarse, aprender unas de otras y apoyarse entre sí, es de esperar que el desarrollo del niño/a y el bienestar tanto de la familia como de la escuela se vean favorecidos, además de que puede influir positivamente en los espacios en los que el niño o la niña se desenvuelve.

Por su parte, Keyser (2006) plantea que los centros de cuidado infantil necesitan tener en mente la participación de las familias, con base en relaciones de respeto mutuo. Tanto las maestras como las familias reconocen la importancia que ambas partes tienen para proveer experiencias formativas que beneficien a los niños y las niñas. En este sentido, un centro focalizado en la familia considera que las relaciones con éstas es el eje del cuidado y la educación infantil. Es por ello que plantea cinco principios que deben guiar la práctica de las educadoras:

1. Reconocer y respetar el conocimiento y experiencia. Significa reconocer que tanto la familia como la educadora tienen algo que aportar a la relación, es decir: las familias poseen un amplio conocimiento de su hijo/a y las educadoras acerca del cuidado y la educación en un centro educativo, y a partir de esto se establece una relación de igualdad en la que se reconocen y respetan los conocimientos y la experiencia que ambas partes tienen.

\section{$-4-$}

Construyendo Comunidades de Aprendizaje: Un Programa de Formación de Educadoras de niños y niñas de o a 6 años. Estrategias de vinculación entre la Familia y la Escuela. Rosa Nashiki, Roxanna Pastor, Miguel Pérez, Rocío Hernández, Leticia Lemus y Carla Ocón. 
2. Crear vías de comunicación bidireccional para compartir información. Se refiere a la importancia de generar oportunidades para escuchar los pensamientos, sentimientos y experiencias de las madres y padres con relación a su hijo/a, así como de la educadora, además de intercambiar información que enriquezca el conocimiento que se posee de cada niño/a.

3. Compartir el poder y la toma de decisiones, es decir, que tanto educadoras como familias deciden de manera conjunta en beneficio de los niños y las niñas.

4. Reconocer y respetar la diversidad. Implica reconocer la individualidad de las educadoras, familias y niños/as; aceptar que cada uno/a proviene de una familia distinta, con una estructura, organización, creencias y cultura particular; y que esta diversidad enriquece las relaciones que se establecen en el centro educativo, además de que brinda oportunidades para incluir en sus actividades aspectos que respondan a ella.

5. Crear redes de apoyo reconociendo la necesidad de las educadoras y las familias de ser escuchadas y acompañadas en el cuidado y educación del niño/a, así como de saber más acerca del cuidado y la educación.

Estos esfuerzos implican establecer vínculos con las familias, mismos que permiten iniciar y mantener relaciones con ellas. Autores como Benson y Martin (2003), Cataldo (1991) y Stacy (1996), describen algunas estrategias que pueden ser empleadas para estos fines, pero que además promueven de manera óptima la participación de las familias en los centros educativos. Dichas estrategias han sido evaluadas desde el punto de vista de los usuarios, reconociendo que aquellas que tienen mayor impacto son las que favorecen el diálogo entre las educadoras y las familias a través de un lenguaje sencillo; o bien las que favorecen la participación de los miembros de las familias en actividades escolares, mismas que van desde ser voluntario dentro del salón de clases hasta participar de manera colaborativa en proyectos específicos (Benson y Martin, 2003; Riojas-Cortez y Bustos, 2003; Christie, 2005; Million, 2003 y Nashiki, 2006).

Cabe resaltar que la elección de la estrategia que habrá de usarse depende de la finalidad que se pretenda lograr para favorecer los vínculos con las familias: mientras que unas están orientadas a establecer comunicación con las familias, es decir, a acercarse y establecer el diálogo, otras se dirigen a favorecer su participación en actividades del centro educativo, es decir, promueven el ingreso al centro para compartir conocimientos y experiencias durante la realización de alguna actividad. Finalmente existen estrategias cuya principal finalidad es brindar información, en cuyo caso pueden ser utilizadas como oportunidades para establecer los primeros contactos con las familias a partir de un tema que sirva como detonador del diálogo. A continuación se definen las estrategias comúnmente utilizadas, de acuerdo a su objetivo, y posteriormente se detalla cada una de ellas. 
Algunas de las estrategias que promueven la participación de las familias en los centros educativos tienen como finalidad establecer comunicación con ellas a través de acciones que promuevan el contacto personal mediante encuentros formales o informales en donde se establezca y mantenga una relación con las madres o padres de familia. Entre ellas se encuentran:

- Encuentros espontáneos. Oportunidades en las que se encuentran frente a las familias para compartir información, escucharlas y conocer un poco más a cada una.

- Entrevistas. Encuentros privados de la madre y/o el padre con miembros del personal del centro educativo con el propósito de brindar asesoría y orientación; en estos encuentros se puede compartir información respecto del desarrollo del niño/a, brindar sugerencias de cuidado y educación o buscar de manera conjunta alternativas para el trabajo con él o ella.

- Visitas domiciliarias. Encuentros con las familias en su domicilio. Resultan un mecanismo efectivo para responder a las necesidades y demandas de las familias, ya que se consideran las rutinas, los problemas, los valores, la comunicación, las normas de conducta y las prioridades de cada una para responder a sus demandas.

También existen aquellas estrategias que promueven la participación de las familias en algunas actividades dentro del salón de clases, en la toma de decisiones en relación a eventos escolares, o bien para colaborar en la organización o asistir a festividades del centro educativo. Entre éstas se encuentran:

- Visitas al salón de clases. Se pueden desarrollar proyectos que permitan la participación de las familias en las actividades del aula, ya sea compartiendo su propia experiencia, en la lectura de cuentos o durante la realización de manualidades. Esto permite que la colaboración entre educadoras y familias sea mejor.

- Proyectos de trabajo. Durante algunos proyectos o necesidades de las escuelas se puede invitar a las familias a colaborar en la realización de actividades o reparación de materiales y juguetes, en arreglos a las instalaciones escolares o en la organización de eventos para recaudar fondos.

Finalmente se encuentran aquellas cuyo principal objetivo es compartir información:

- Materiales impresos. Son escritos en donde se comunican situaciones relacionadas con el desarrollo del niño/a o acerca de las actividades planeadas, por ejemplo trípticos, hojas de información básica, boletines y circulares informativas.

\section{$-6-$}

Construyendo Comunidades de Aprendizaje: Un Programa de Formación de Educadoras de niños y niñas de o a 6 años. Estrategias de vinculación entre la Familia y la Escuela. Rosa Nashiki, Roxanna Pastor, Miguel Pérez, Rocío Hernández, Leticia Lemus y Carla Ocón. 
- Tableros de anuncios. Son avisos escritos en donde se informa acerca de aspectos de relevancia para la comunidad escolar o con asuntos relacionados con el desarrollo de los niños y las niñas, por ejemplo los carteles y los murales.

- Reuniones con padres. Son situaciones generadas por el centro educativo en donde las madres y los padres se reúnen a dialogar acerca de eventos del centro o en los que se les orienta e informa a través de conferencias, talleres o juntas informativas en aspectos relacionados con el desarrollo de sus hijos e hijas.

\section{Nota importante}

Recuerda que sea cual sea la estrategia que utilices es necesario tener en mente que para : favorecer la participación de las familias es conveniente:

- Reconocer que cada día es una oportunidad para aprender más sobre el niño/a y su familia.

- Investigar el nombre de personas significativas en la vida del niño o la niña (su mamá, abuelo/a, etc.).

- Identificar los momentos más apropiados para establecer comunicación con las familias, cuidando de encontrar espacios para dialogar de manera directa con cada una de ellas.

- Ofrecer información de manera verbal, si es posible diariamente, acerca de cómo: estuvo el día.

- Solicitar a cada familia información acerca de su niño o niña al menos una vez a la semana. Por ejemplo, "¿con quién juega Lucy cuando está en casa?".

En las páginas que siguen se describen las estrategias propuestas por Cataldo (1991), Stacy (1996), Benson y Martin (2003), mismas que han demostrado ser de utilidad para promover y facilitar la participación de las familias. Dichas estrategias se encuentran agrupadas en dos grandes apartados:

1. Encuentros personales: encuentros espontáneos, juntas informativas, visitas al salón de clases, proyectos de trabajo, entrevistas, pláticas, talleres y visitas domiciliarias. 
2. Materiales impresos: trípticos, hojas de información básica (también conocidas como "hojas informativas"), carteles, murales, boletines.

Para cada apartado se presenta una breve introducción y consideraciones generales para su desarrollo. Se describe cada una de las estrategias y se explica su objetivo, características y cómo realizarla o elaborarla. En la mayoría de los casos se incluye un ejemplo en el apartado de los anexos. Finalmente se presenta una propuesta de evaluación para las estrategias implementadas.

-8-

Construyendo Comunidades de Aprendizaje: Un Programa de Formación de Educadoras de niños y niñas de o a 6 años. Estrategias de vinculación entre la Familia y la Escuela. Rosa Nashiki, Roxanna Pastor, Miguel Pérez, Rocío Hernández, Leticia Lemus y Carla Ocón. 


\section{Encuentros personales}

Son momentos en los que las educadoras pueden dialogar de manera directa con las familias para conocerse personalmente y platicar abiertamente. La frecuencia con lo que se lleven a cabo definirá la mayor o menor participación de las familias.

Estas situaciones son generadas por las educadoras. Pueden ser de manera individual o en grupos, y en ambos casos deben permitir el establecimiento de diálogo con cada una de las familias para fomentar su participación haciéndoles llegar el mensaje de que son bienvenidas y respetadas y que estás interesada en conocer más acerca de ellas.

\section{Recomendaciones generales para su realización}

(:) Generar oportunidades para estar accesible para las familias, es decir, establecer un momento para dialogar de manera directa con las familias e informarles de ello.

:) Utilizar un lenguaje sencillo que permita claridad en la comunicación.

(:) Compartir ejemplos cotidianos que abra canales de comunicación y permita el intercambio de información.

(:) Estar disponible para escuchar y atender de manera oportuna las inquietudes de las familias.

(:) Cumplir con el horario establecido, y en caso de que exista algún cambio, avisarlo oportunamente.

(:) En el caso en que se requieran materiales, revisar con anterioridad si se cuenta con ellos antes de encontrarse con las familias.

\section{Son de utilidad cuando:}

- Se desea fomentar la comunicación entre el hogar y el centro educativo para generar semejanzas en los ambientes.

- Se desea fomentar la cercanía entre las educadoras y las familias durante su participación en un proyecto del salón de clases de acuerdo a un tema relacionado con el plan de trabajo.

- Se requiere de un mayor conocimiento del niño/a y de su familia para promover su desarrollo y aprendizaje de manera integral, considerando los contextos en donde se desarrolla (casa y escuela).

- Se requiere obtener información sobre acontecimientos y actividades que no se pueden observar directamente.

- Algunos/as niños/as de la sala requieren de atención individualizada y se requiere mantener comunicación con su familia para dar seguimiento y compartir información.

- Se requiere dar orientación cercana o directa a las familias. 


\section{Encuentros espontáneos}

Consiste en establecer y mantener vínculos con las familias a través de encuentros espontáneos, es decir, en los momentos en los cuales aparentemente no hay una intención de dialogar sino que se da la oportunidad para hacerlo. Se establecen relaciones positivas con las familias en momentos cotidianos como son la llegada o salida, cuando se encuentra a la familia en el trayecto hacia el centro educativo o cuando la familia asistió al centro educativo sin una cita formal (ejemplo en anexo 1).

\section{Objetivo:}

Establecer y mantener relaciones positivas con las familias a través de encuentros informales.

\section{Características:}

- Se establece contacto directo con las familias en los momentos en los que te encuentras con ellas para hacerles sentir que son bienvenidas, que son importantes para ti y que te da gusto verles.

- Son encuentros breves pero hacen sentir importante a la familia en tanto que se intercambia información que es relevante para ella y se le hace sentir que en el centro educativo conocen y respetan a su hijo/a.

\section{Cómo realizarla:}

- Acércate a la familia; si te es posible recibe y despídete personalmente del niño/a y su familia.

- Saluda de manera cordial y entusiasta a cada niño/a y a su familia. Si llamas al niño/a por su nombre la familia sabrá que lo/a conoces y confiará en ti.

- Comparte de manera informal un hecho importante de su hijo/a, por ejemplo: "ayer Arturo se divirtió mucho cuando jugamos con harina"; o bien invítalos personalmente a asistir a algún evento, compartiendo lo importante que sería para ti poder contar con su presencia.

- $\quad$ Establece contacto visual con el niño/a y su familia mientras les compartes algo. 


\section{Juntas informativas}

Reuniones que se llevan a cabo con cierta periodicidad, previa convocatoria del centro educativo. En ellas se comparte con las familias los avances y logros de los niños y niñas, así como las necesidades del grupo. Normalmente se aprovechan estos encuentros para trasmitir información acerca del desarrollo y aprendizaje de los niños y las niñas, por ejemplo en las reuniones que se realizan para compartir los resultados de las evaluaciones (ejemplo en anexo 2).

\section{Objetivo:}

- Informar sobre los logros, avances y necesidades de los niños y las niñas de un grupo.

\section{Características:}

- $\quad$ Son reuniones que se llevan a cabo de manera preestablecida.

- Cuentan con una agenda de temas de interés común.

- Existe un espacio para compartir inquietudes o necesidades particulares.

\section{Cómo realizarla:}

- Elabora una invitación dirigida a las familias en donde se especifique el objetivo, el horario y lugar de la reunión.

- Realiza la junta en un horario que sea accesible para la mayoría de las familias, con el fin de asegurar su asistencia.

- Elabora una agenda de los temas que se van a discutir, de preferencia en orden de prioridad, y deja un espacio para comentarios adicionales.

- Prepara con anticipación el espacio físico y los recursos que necesitas para el desarrollo de la junta, incluyendo al personal que estará a cargo.

- Durante la reunión, realiza comentarios grupales de los avances, logros y necesidades; el tiempo no permite desviar la atención a particularidades o situaciones especiales.

- Al final de la reunión puedes dirigirte de manera particular con aquellas familias que requieran apoyo o ameriten una atención individualizada. 


\section{Visitas al salón de clases}

Son encuentros en el salón de clases entre las familias, los niños y las niñas y el personal educativo. Se organizan momentos en los que la familia puede ingresar al salón ya sea para observar una clase o para participar en actividades previamente diseñadas.

En algunos centros educativos se conocen como "programas de puertas abiertas" o participación en clases (ejemplo en anexo 3).

\section{Objetivo:}

- Brindar un espacio en donde las familias conozcan el centro educativo en cuanto a las instalaciones, horario y actividades de sus hijos/as al compartir el trabajo que se realiza cotidianamente.

- Promover espacios de vinculación entre el personal educativo y las familias a través de la realización de actividades conjuntas en las que pueden conocer lo que hacen los niños/as, sus avances y algunas estrategias útiles para realizar en casa.

\section{Características:}

- Se realiza una actividad de manera conjunta entre las familias, los niños y niñas y las educadoras en las cuales la educadora puede dialogar de manera directa con cada una de las familias y así conocerlas un poco más. A través de las visitas las familias tienen la oportunidad de conocer a la educadora y la manera en la que se relaciona con su hijo/a, así como a los compañeros y compañeras de su hijo/a.

- Permiten el diálogo directo entre las educadoras y las familias, así como la expresión de inquietudes y necesidades de ambas partes.

- Durante estas visitas las familias pueden realizar un proyecto en común, como lo es la elaboración de materiales o bien compartir un momento en el salón de su hijo/a.

\section{Cómo realizarlas:}

- Calendariza las visitas de acuerdo a las posibilidades de la institución. Promueve la asistencia de las familias a través de carteles, folletos e invitaciones para que participen en las visitas.

- Da la bienvenida y haz una presentación de las familias y el personal involucrado. Posteriormente explica de manera breve la agenda del día y las actividades que se llevarán a cabo, así como el objetivo de la visita.

- Considera el número de familias que asistirán para elegir las actividades a realizar; de preferencia trabaja en pequeños grupos, pero asegúrate de tener la oportunidad de pasar un momento con cada familia y en cada grupo.

- Una vez finalizada la actividad permite que las familias compartan su experiencia entre ellas; toma notas de ello para después poder comunicarlo a las que no pudieron estar presentes en la reunión y da oportunidad de que las familias expresen sus dudas e inquietudes acerca de lo ocurrido durante su permanencia en el salón y aclara sus dudas.

- Solicita que las familias evalúen la visita a través de un cuestionario de opinión en donde expresen su impresión, lo que aprendieron de su hijo/a o del grupo, y alguna sugerencia. 


\section{Proyectos de trabajo}

Son actividades incluidas en el plan de trabajo de la educadora en donde las familias pueden compartir sus conocimientos y desarrollar alguna actividad con el grupo de niños/as y la educadora (ejemplo en anexo 4). En estos encuentros los padres y/o las madres pueden informar sobre las características de su profesión, facilitar la visita a su centro de trabajo, leer cuentos, etc.

Los padres y madres son un valioso recurso con que cuentan las educadoras para desarrollar el programa escolar, pero esto exige cierto esfuerzo de coordinación y organización: listas de oficios de los padres y madres, horarios disponibles, etc.

\section{Objetivo:}

- Brindar un espacio en donde las familias se involucren en las actividades de sus hijos/as.

- Promover espacios de vinculación entre el personal educativo y las familias a través de la realización de actividades conjuntas.

- Fomentar la participación de las familias en la realización de actividades, así como en la toma de decisiones relacionadas con el desarrollo y aprendizaje de su hijo/a.

\section{Características:}

- Son encuentros en el salón de clases entre las familias, los/as niños/as y la educadora en los que se realizan actividades que permiten a estas últimas conocer a las familias y sus intereses, y fomentan el diálogo entre educadoras, familias, y niños y niñas.

- Pueden ser encuentros en los que asiste una familia a la vez, o más de una, dependiendo del objetivo del proyecto. Cuando asiste sólo una familia esto permite a la educadora establecer una relación directa con ella.

- Permiten a las familias conocer a los niños y niñas que conforman el grupo de su hijo/a, así como a la educadora y su forma de trabajo.

- Fomentan la confianza entre la familia y el personal educativo.

- En la medida de lo posible se dejan abiertos los horarios considerando y respetando las posibilidades de las familias.

\section{Cómo realizarlos:}

- Diseña actividades que permitan la participación de las familias en distintos proyectos, los cuales pueden ser acondicionar el salón de clases, compartir su profesión cuando se relacione con el tema, realizar una actividad conjunta como cocinar o leer cuentos, entre otros.

- Invita a las familias a participar en algún proyecto de trabajo explicándoles con anterioridad el objetivo; de preferencia relaciona el proyecto con su planeación; así las familias contribuirán también a la promoción de habilidades en las niñas y los niños.

- Elabora una agenda para la participación de las familias, en donde tengas presente el día en el que se presentará cada una.

- Durante la visita de una familia para la realización del proyecto, dale la bienvenida y preséntala al grupo; invita a la familia a presentarse y a comentar lo que van a hacer; pide a los niños y niñas que 
se presenten y hazles saber el gusto que es recibirla para realizar la actividad con ella. En todo momento permanece con la familia apoyando la realización de la actividad.

- Aprovecha el encuentro con la familia para dialogar acerca de lo que hacen en casa, así como de la realización de la actividad. Puedes aprovechar para comentar algunas anécdotas de su hijo/a, comentar inquietudes y brindar algunas sugerencias.

- Considera cualquier oportunidad para que las familias se involucren en las actividades del grupo; de esta manera, además de promover la participación favorecerás la comunicación con las familias y conocerás de una mejor manera a cada niño/a de tu grupo. 


\section{Entrevistas}

Son encuentros cara a cara entre la educadora y la familia, con el fin de conocer mejor sus ideas, sentimientos y forma de actuar. Estos encuentros son dirigidos hacia la comprensión de las perspectivas que tienen respecto de sus vidas y experiencias.

\section{Objetivo:}

Compartir información relevante para conocer a la familia y su contexto familiar, así como su desarrollo a través del diálogo entre la educadora y la familia, es decir, compartir su conocimiento acerca del niño/a para enriquecer la información que cada parte tiene de él/ella.

\section{Características:}

- Siguen el modelo de una conversación entre iguales y no de un intercambio formal de preguntas y respuestas. Para lograrlo se debe utilizar un lenguaje sencillo.

- La educadora elabora con anterioridad una guía de entrevista que le permite conducirla.

- La familia tiene una participación activa durante la entrevista, ya que comparte su conocimiento acerca de su hijo/a. El rol de la educadora consiste en compartir sus propios modos de ver el desarrollo del niño/a, compartir algunas anécdotas que ilustren cómo suceden las actividades o conductas del niño/a, así como promover que la familia comparta su punto de vista.

- Incluye 5 momentos:

1. Recepción: se da la bienvenida a la madre/padre y se establece un ambiente de confianza.

2. Establecimiento de la relación: se logra compartiendo los objetivos de la entrevista, expresando la necesidad de la misma y escuchando el punto de vista de la familia.

3. Parte central: es el momento en donde se comparte la información tanto por parte de la educadora como de la familia.

4. Acuerdos: se generan compromisos por ambas partes (educadora y familia) respecto del objetivo de la entrevista.

5. Cierre y despedida: es el momento para compartir sus dudas y resolverlas antes de terminar la entrevista, o bien para que ambas partes, sobre todo la familia, exprese las inquietudes que no fueron consideradas en otros momentos de la entrevista. Finalizar la entrevista.

\section{Cómo realizarla:}

Para llevar a cabo una entrevista es necesario realizar acciones antes del encuentro con la madre/el padre, durante el encuentro con él/ella y después de que se ha llevado a cabo.

\section{a) Antes de la entrevista:}

- Averiguar quién/quiénes es/son la/s persona/s que le pueden brindar más información respecto del niño/a; en ocasiones es recomendable citar a la abuela, tía u otro familiar que se encuentra al cuidado del niño/a.

- Informar a la familia el interés y utilidad de la entrevista, explicando los objetivos y las condiciones de su desarrollo, así como el lugar y la hora del encuentro.

- Realizar observaciones que le permitan obtener la mayor información posible respecto de la situación del niño/a, así como el planteamiento de dudas e inquietudes al respecto. 
- Elaborar una guía de entrevista que incluya los momentos que la componen, así como las acciones a realizar de su parte.

\section{b) Durante la entrevista}

\section{Recepción}

- Recibe personalmente a la familia e invítalos a pasar al lugar de la entrevista. Asegúrate de conocer el nombre de las personas que acudieron para poder comunicarte cercanamente con ellas.

- Ten en mente que el principio fundamental de la entrevista es proveer un contexto en el que la familia pueda expresar sus ideas en términos propios.

\section{Establecimiento de la relación}

- Saluda cordialmente a la familia y dale la bienvenida.

- Realiza algún comentario en relación al niño/a que haga sentir a la familia que lo/la conoce y que quiere compartir su conocimiento con la familia.

- Muestra empatía, es decir, trasmite a la familia interés por lo que comparten, confianza a través del conocimiento que posees de su hijo/a pero también de lo que te cuentan acerca de cómo es en casa y muestra credibilidad respecto de lo que te dicen, es decir, que para ti lo que la familia te comparte es válido en tanto que es su punto de vista.

\section{Parte central}

- Utiliza la guía de la entrevista como una estrategia para abarcar los temas que deseas complementar y no como una serie de preguntas y respuestas, es decir, deja que la charla sea libre y trata de obtener la información necesaria a través de ella. Sólo en caso necesario realiza preguntas específicas asegurándote de que sean abiertas, ya que éstas permiten el diálogo. Utiliza anécdotas que ejemplifiquen lo que deseas trasmitir a la persona entrevistada y que complementen lo que ella comparte, o bien den un nuevo punto de vista de la situación.

- Muestra comportamientos adecuados en relación a la manifestación de sentimientos, es decir, responde a la manera en como la otra persona se conduce durante la charla, por ejemplo, si cuenta una anécdota graciosa y se ríe, hazlo tú también.

- Toma notas de la información relevante que pueda ser utilizada posteriormente, o de aquellos mensajes que desees retomar en otro momento de la entrevista.

- Resume periódicamente la información obtenida para comprobar que el mensaje que estás captando es correcto.

\section{Acuerdos}

- Pregunta a la familia qué pueden hacer para apoyar a su hijo/a; bríndale algunas alternativas en caso de que no tengan alguna opción y pregunta qué de ello pueden realizar, explicando la importancia de llevarlo a cabo.

- Muéstrate prudente y no trates de imponer u obligar a hechos o sentimientos que la familia no desea.

\section{Cierre y despedida}

- Comunica a la familia que la entrevista está por terminar, y pregunta si tienen algún otro comentario que deseen compartir. En caso de ser posible discútelo en esa ocasión; en caso contrario acuerda con ellos/ellas las condiciones de una nueva entrevista.

- Agradece a la familia su asistencia, mostrándote abierta para cualquier comentario o inquietud de su parte.

-16-

Construyendo Comunidades de Aprendizaje: Un Programa de Formación de Educadoras de niños y niñas de o a 6 años. Estrategias de vinculación entre la Familia y la Escuela. Rosa Nashiki, Roxanna Pastor, Miguel Pérez, Rocío Hernández, Leticia Lemus y Carla Ocón. 
- Revisa las notas que tomaste durante la entrevista para elaborar conclusiones acerca de la información recabada.

- Comparte con las personas involucradas la información obtenida. Reconoce aquella que sirva para entender la situación y que sea relevante.

- Utiliza el conocimiento adquirido durante la entrevista para complementar las acciones a realizar con el niño/a, ya sea en el centro educativo o en su hogar. 


\section{Pláticas}

Son exposiciones orales o conferencias de corta duración sobre un tema específico en un horario que facilite la asistencia de las familias y no interfiera con sus horarios laborales. La exposición puede enriquecerse con preguntas y respuestas.

\section{Objetivo:}

Brindar información acerca de un tópico de interés para la comunidad escolar, un grupo o una etapa del desarrollo.

\section{Características:}

- Son diseñadas para brindar información a un grupo de personas.

- Orientan a un grupo de personas respecto de un tema en particular.

- Tienen una duración que puede ser de una a dos horas.

- Se puede incluir una sección de preguntas y respuestas al finalizar la charla, que dé oportunidad de complementar el tema a través de las dudas de los/as asistentes.

\section{Cómo realizarlas:}

- Identifica las necesidades e intereses de las familias. Puede ser a través de una encuesta o cuestionario para conocer sus necesidades.

- Selecciona un tema de interés para las familias, de preferencia aquel que tenga que ver con una situación que represente un reto para la etapa o algo que esté ocurriendo en la vida de los niños y las niñas y sus familias.

- Identifica en la literatura algunas ideas centrales que desees transmitir a las familias y que sean relevantes para su vida, es decir, que se relacionen directamente con lo que está ocurriendo con relación a su hijo/a. Puedes elaborar una hoja de información básica o un tríptico con la información relevante para entregarla a las familias al finalizar la plática.

- Realiza algunas observaciones de cómo en el centro educativo los niños y las niñas y el personal educativo se enfrentan a situaciones relacionadas con el tema e incorpora algunas anécdotas que te permitan ejemplificar los contenidos, aún cuando no incluyan los nombres de las personas involucradas.

- Elabora una invitación en donde se especifique el objetivo, el horario y lugar de la reunión.

- Acude de manera anticipada al horario acordado para asegurarte de que el espacio es adecuado para las que asistirán y que cuentas con lo necesario para dar la conferencia. 


\section{Talleres}

Son espacios educativos que promueven la adquisición o el fortalecimiento de habilidades y destrezas a partir de la realización práctica de tareas propuestas, y que cuentan con la orientación y acompañamiento a los/as participantes en su proceso de aprendizaje.

También son espacios para compartir experiencias y aprender a partir de las experiencias de otras personas; esto permite favorecer la creación de redes de apoyo entre las familias y acompañarse en el proceso de cuidado y atención de su hijo/a.

\section{Objetivo:}

Brindar información acerca de un tema específico, así como ofrecer oportunidades para la adquisición y desarrollo de habilidades.

\section{Características:}

- Se conforma un grupo de asistentes que comparten una característica; funcionan mejor cuando se organizan conforme a la etapa de desarrollo su hijo/a, pues constituye también un espacio para compartir experiencias.

- El número de asistentes no debe exceder a 12, ya que este número permite la participación de todos, a menos que existan condiciones para admitir a más personas, tales como número de facilitadoras/es, espacio físico o recursos materiales.

- Se cuenta con un facilitador/a o un equipo de trabajo responsable de dirigir las actividades, mismo que es experto en el tema.

- Se cuenta con actividades teórico-prácticas que permiten la adquisición de conocimientos y habilidades por parte de los/as asistentes.

\section{Cómo realizarlos:}

- Identifica las necesidades e intereses de las familias; puede ser a través de una encuesta o cuestionario para conocer sus necesidades. Identifica los temas de mayor interés, elabora un listado y analiza su impacto. Además, analiza las prioridades de la institución y cotéjalas con las necesidades de las familias.

- Selecciona un tema de interés para las familias, de preferencia uno que tenga que ver con una situación que represente un reto para la etapa o algo que esté ocurriendo en la vida de los/as niños/as y sus familias.

- Considera actividades y situaciones que permitan la reflexión, así como el intercambio de conocimientos de los participantes. Incorpora a las dinámicas anécdotas similares a las que viven las familias con sus hijos e hijas y que has observado en el centro escolar.

- Realiza una convocatoria para la participación de las familias, de ser posible en el horario que sea accesible para la mayoría. Considera el número de sesiones más apropiado para los asistentes y para el tema que se va a tratar. Lleva a cabo el taller de acuerdo al horario establecido.

- Genera acuerdos con los participantes de cómo se va a llevar el taller; establece con ellos y ellas las reglas del grupo; asegúrate de que se establezcan acuerdos acerca de la confidencialidad, el respeto al turno y al horario, hablar en primera persona y compartir cuando se quiera y se pueda

- Considera una manera en la que los participantes puedan evaluar cada una de las sesiones. Además, analiza cada una de las sesiones realizadas y haz los ajustes pertinentes de acuerdo a lo observado en la misma, tomando en cuenta los comentarios de los participantes. En caso de que cuentes con otras personas que colaboren en el diseño e implantación, discute con ellas su punto de vista y lleguen a acuerdos para realizar los ajustes pertinentes. 


\section{Visitas domiciliarias}

Son encuentros con las familias en su domicilio, en donde se realizan acciones de acuerdo a los objetivos planteados y discutidos con ellas. Permiten brindar atención y asesoría individualizada a las familias en su contexto, así como realizar intervenciones de manera inmediata en el contexto familiar.

\section{Objetivo:}

Fomentar la relación con las familias, estableciendo vínculos entre ellas y la educadora.

\section{Características:}

- Responden a las necesidades y demandas de las familias ya que, al desarrollarse en su hogar, se toman en cuenta las rutinas, los valores, la comunicación, las normas de conducta y las prioridades de cada familia.

- Promueven vínculos entre el hogar y el centro educativo al compartir información relevante de ambos contextos.

- Tienen una duración de máximo una hora, en un horario establecido y acordado con anterioridad con la familia.

- Participan en la visita las personas significativas para el niño/a en las condiciones más parecidas posibles respecto de la rutina cotidiana que sigue la familia en casa.

- La persona que realiza la visita respeta y acepta a la familia, se reconoce como su aliada (ver anexo 5: las habilidades de un/a visitador/a).

\section{Cómo realizarlas:}

- Elabora una agenda de actividades con cada una de las familias a las cuales vas a visitar, considerando fechas y propósitos de las mismas. Elabora un programa general de las visitas y compártelo con las familias; debes estar abierta a sus necesidades e inquietudes. Las actividades planeadas deben ser revisadas de manera continua para realizar los ajustes que se requieran, dependiendo de lo que necesite cada familia.

- Inicia y termina la visita a la hora acordada; recuerda que eres un visitante y como tal necesitas respetar el tiempo de las familias, así como ellas el tuyo.

- Comparte con las familias el objetivo y la agenda de actividades, teniendo en mente que las actividades o contenidos de las visitas pueden variar de una familia a otra.

- Utiliza medios para recuperar lo que observes durante la visita, tales como una bitácora o un formato en donde puedas plasmar la experiencia, los logros y necesidades observadas.

- En caso de ser posible comparte con otras educadoras tu experiencia y solicita retroalimentación; para ello puedes utilizar el medio anterior como estrategia para compartir lo sucedido, o bien, acude a la visita con otra/s educadora/s de tu mismo centro educativo que tenga experiencia y que pueda brindarte asesoría.

- Antes de cada visita asegúrate de haber observado al niño/a en el centro escolar, de tal manera que puedas compartir con las familias anécdotas relacionadas con su hijo/a y fomentes tu relación con ella.

Construyendo Comunidades de Aprendizaje: Un Programa de Formación de Educadoras de niños y niñas de o a 6 años. Estrategias de vinculación entre la Familia y la Escuela. Rosa Nashiki, Roxanna Pastor, Miguel Pérez, Rocío Hernández, Leticia Lemus y Carla Ocón. 


\section{Materiales impresos}

Son escritos que se elaboran con el propósito de fomentar la participación de las familias a partir de información relativa a situaciones relacionadas con el desarrollo del niño/a o a las actividades a realizar, entre otros temas. Pueden ser trípticos, hojas de información básica, murales, carteles y circulares informativas.

\section{Recomendaciones generales para su elaboración}

Cuando se trata de elaborar materiales impresos es necesario tener en consideración las siguientes recomendaciones para facilitar la lectura y la identificación de ideas centrales:

国 Usar párrafos y frases cortas. Para ello se pueden utilizar viñetas, asteriscos, puntos o cualquier otro símbolo que permita distinguir un párrafo o frase de otra.

国 Usar subtítulos que permitan separar una sección de otra y su rápida identificación, o bien, subrayar o resaltar palabras clave, o aquello que sea de mayor importancia.

国 Evitar párrafos muy extensos y páginas con párrafos no uniformes en cuanto a extensión y diseño. La variedad favorece la atención al texto, por lo que si deseas resaltar una información deberás utilizar otro tipo de letra o diseño.

国 Seleccionar un tipo de letra apropiado para tu texto. Recuerda que debe ser legible. También puedes hacer uso de letras mayúsculas para llamar la atención del lector o formular preguntas que guíen la lectura.

国 Utilizar espacio sencillo o doble en sus textos para distinguir algún mensaje del resto.

\section{Son de utilidad cuando:}

- Se desea compartir información a un grupo extenso de personas en un mismo tiempo y no hay muchas oportunidades para dialogar de manera directa.

- Es necesario que gran parte de la población esté informada en poco tiempo.

- Se desea dar respuesta a una problemática o situación común a las familias a través de un documento escrito, el cual puede ser un aliado para la realización de sugerencias o bien un mecanismo para compartir información de manera impersonal. 


\section{Trípticos}

Son escritos breves en los que se expone información puntual sobre un tema específico y que al mismo tiempo brinda recomendaciones sencillas y prácticas para promover o atender una situación particular. Utilizan un lenguaje sencillo y claro, con indicaciones fáciles de seguir, y sobre todo debe elaborarse de manera que invite a leerlo, es decir, su diseño debe ser agradable, la cantidad de texto y de imágenes debe estar balanceado y estas últimas deben ser alusivas al tema (ejemplo en anexo 6).

\section{Objetivo:}

Compartir información relevante de manera escrita acerca de un aspecto del desarrollo o aprendizaje relacionado con la etapa del desarrollo de los/as niños/as, así como brindar alternativas para promoverlo.

\section{Características:}

- Generalmente están elaborados en hoja tamaño carta, dividida en tres partes por cada cara de la hoja, de tal manera que cuenta con 6 columnas para el contenido.

- Poseen información relevante acerca de un tópico de interés, así como sugerencias específicas.

- Se organizan en pequeños apartados que puntualizan la información en frases breves, lo cual facilita que sean recordadas.

- Los mensajes principales están acompañados de imágenes que los ejemplifican. Para ello se recomienda tomar fotografías de las niñas y los niños en situaciones reales del centro escolar que hagan referencia a lo que se desea transmitir.

\section{Cómo elaborarlos:}

- Selecciona un tema de interés para las familias, de preferencia uno que tenga que ver con alguna situación que represente un reto para la etapa o algo que esté ocurriendo en la vida de las niñas y los niños y sus familias.

- Analiza e identifica el objetivo central del tríptico que deseas elaborar. Selecciona dos o tres mensajes relacionados con el objetivo que deseas transmitir a las familias y redacta frases cortas que contengan la información básica que les permitan comprender el tema, las cuales deberán estar redactadas en frases en positivo.

- Incluye algunas sugerencias que permitan a las familias comprender y saber cómo apoyar a su hija/o.

- Distribuye la información en pequeños apartados para que la información que quieres trasmitir sea clara. Puedes utilizar subtítulos o preguntas para dividir cada sección.

- Abre un espacio para compartir las inquietudes o sugerencias de las familias o el personal.

-22-

Construyendo Comunidades de Aprendizaje: Un Programa de Formación de Educadoras de niños y niñas de 0 a 6 años. Estrategias de vinculación entre la Familia y la Escuela. Rosa Nashiki, Roxanna Pastor, Miguel Pérez, Rocío Hernández, Leticia Lemus y Carla Ocón. 


\section{Hojas de información básica}

Son resúmenes que recogen las ideas centrales de un tema específico y que permiten trasmitir información concreta a las familias o a la persona a la cual van dirigidas. Mediante las hojas de información básica se comparten experiencias y se brindan sugerencias específicas. A través de la narración se ejemplifican los conceptos básicos para la comprensión de un tema y se plantean recomendaciones en beneficio del desarrollo infantil (ejemplo en anexo 7).

\section{Objetivo:}

Compartir información relevante, de manera breve, acerca de un aspecto del desarrollo resaltando los puntos básicos que se requieren para comprender el tema, así como algunas sugerencias breves y prácticas que permitan realizar acciones para la promoción del desarrollo y aprendizaje de las niñas y los niños.

\section{Características:}

- Resumen de un tema específico, con una extensión de no más de dos cuartillas, es decir, una hoja por ambas caras.

- Contienen información básica de un tema, necesaria para la comprensión del mismo y la implantación de estrategias.

- Contienen anécdotas o ejemplos reales que permiten la comprensión del tema.

- Sirven como medio de comunicación y transmisión de la información con otros miembros de la familia, aún cuando no hayan asistido a la exposición del tema, plática o taller.

- Sirven como refuerzo para recordar estrategias de apoyo y sugerencias brindadas.

\section{Cómo elaborarlas:}

- Selecciona un tema de interés para las familias, de preferencia aquel que tenga que ver con una situación que represente un reto para la etapa o algo que esté ocurriendo en la vida de las niñas y los niños y sus familias.

- Analiza qué es lo más importante del tema que las familias necesitan conocer y tener en mente para la promoción del desarrollo y aprendizaje de su hija o hijo y desarrolla el contenido de la hoja teniendo en mente cuáles son los mensajes que te interesa compartir y la importancia de que los comprendan.

- Redacta párrafos cortos que contengan poca información, con un lenguaje sencillo que permita la comprensión por parte de las familias; incluye anécdotas relacionadas con tus observaciones en el centro escolar. Ten en cuenta que deberás presentar el contenido en una o dos páginas.

- De ser posible incluye imágenes o fotografías que ejemplifiquen lo que deseas trasmitir y que faciliten la comprensión del contenido.

- Incluye las referencias bibliográficas que permitan a las familias profundizar sus conocimientos acerca del tema abordado. 


\section{Carteles}

Son escritos que permiten compartir información acerca de un evento o actividad que se realizará en el centro educativo. También pueden expresar recomendaciones para realizar alguna actividad que permita promover el desarrollo infantil (ejemplo en anexo 8).

\section{Objetivo:}

Informar a las familias acerca de un evento específico, o bien brindar información concreta acerca de algún tema.

\section{Características:}

- Contienen un mensaje que quiere comunicarse a las familias; puede ser un evento, una actividad o una recomendación.

- El mensaje es corto y puede ir acompañado de una imagen que ayude a ser recordado.

- Es colocado en un espacio visible para las familias.

- Pueden ser:

a) Fotografías de habilidades

b) Cartulinas de sugerencias

\section{Cómo elaborarlos:}

- Selecciona un tema de interés para las familias, de preferencia aquel que tenga que ver con una situación que represente un reto para la etapa o algo que esté ocurriendo en la vida de los niños y las niñas y sus familias.

- Elabora uno o más mensajes que desees compartir; procura que sean cortos, de tal manera que puedan ser recordados con facilidad.

- Si tu cartel es para informar algún evento, asegúrate de incluir una breve descripción, objetivo, fecha, hora y lugar de reunión, así como formas de inscripción.

- Ejemplifica el mensaje con una imagen que lo represente; puede ser una fotografía o un dibujo.

Fotografías de habilidades

1. Elegir un área y una habilidad.

2. Observar al niño o niña y tomar la fotografía de acuerdo a la habilidad elegida.

3. Pegar la fotografía en una hoja; describir la habilidad y lo que ejemplifica la foto.

4. Invitar a compartir la manera como los niños/as realizan la habilidad en casa.

Cartulina de sugerencias

1. Identifica una habilidad que estés promoviendo en tu sala y que desees que las familias también lleven a cabo en casa.

2. Describe brevemente lo que deseas promover, considerando los motivos por los cuales es importante hacerlo.

3. Describe un momento del día en el que se puede promover la habilidad, considerando que sea durante una actividad cotidiana; esto aumenta la posibilidad de que las familias lo puedan realizar.

4. Coloca la cartulina en un espacio visible, y cuando tengas oportunidad dialoga directamente con las familias para saber cómo están promoviendo la habilidad, o bien puedes reservar un espacio en el cartel para que compartan sus experiencias.

Construyendo Comunidades de Aprendizaje: Un Programa de Formación de Educadoras de niños y niñas de 0 a 6 años. Estrategias de vinculación entre la Familia y la Escuela. Rosa Nashiki, Roxanna Pastor, Miguel Pérez, Rocío Hernández, Leticia Lemus y Carla Ocón. 


\section{Murales}

Son espacios que ofrecen a las familias información de manera constante, mediante montajes y collages de distintos materiales (fotos, recortes de prensa, titulares a mano o recortados, diagramas, dibujos, etc.).

En los murales las educadoras pueden compartir con las familias lo que sucede en las aulas mediante fotos, trabajos y creaciones de las niñas y los niños; también sirven para presentar los resultados de proyectos y realizar invitaciones a las familias, entre otras cosas (ejemplo en anexo 10).

\section{Objetivo:}

Informar sobre algún tema común a un grupo de personas, de manera gráfica.

Recoger información de las familias acerca de algún tema y promover su participación.

\section{Características:}

- Contienen mensajes cortos acerca de algún tema en específico, los cuales permiten comprender la información brindada. Estos mensajes pueden transmitirse en esquemas o en viñetas, de tal manera que sea fácil reconocerlos y recordarlos.

- Los mensajes están acompañados de imágenes que permiten una mejor comprensión del tema y que facilitan su recuerdo. Si las imágenes son fotografías de niños y niñas del centro educativo resultará más llamativo.

- Incluyen un espacio en el que las familias obtienen algunas sugerencias para realizar acciones relacionadas con el tema.

- Pueden ser murales informativos o interactivos. Los informativos permiten brindar información que puede resultar útil para abrir canales de comunicación con las familias y promover el diálogo acerca del tema abordado. Los murales interactivos permiten intercambiar información a través de la misma estructura del mural, a reserva de que en otro momento se pueda dialogar acerca de su contenido.

- $\quad$ El mural interactivo se divide en 2 secciones:

a. Parte informativa: donde se puede compartir con las familias las ideas centrales sobre un tema en específico, como el proceso de adaptación, la alimentación de los lactantes, el desarrollo del lenguaje, etc.

b. Parte interactiva: es un espacio en donde las familias escriben sus comentarios, vivencias o preguntas relacionadas con el tema que se expone en el mural. Esta información deberá ser retomada por la educadora, contestando las preguntas o compartiendo la información pertinente.

\section{Cómo elaborarlos:}

- Selecciona un tema de interés para las familias, de preferencia aquel que tenga que ver con una situación que represente un reto para la etapa o algo que esté ocurriendo en la vida de los/as niños/as y sus familias.

- Selecciona dos o tres mensajes que desees compartir con las familias y elabora oraciones sencillas y cortas que permitan comprender los mensajes.

- Ejemplifica los mensajes con imágenes que los representen; pueden ser fotografías de los/as niños/as.

- Invita a las familias a que periódicamente colaboren con la elaboración de un mural con información de su hijo/a, por ejemplo al inicio del ciclo escolar, o en un día festivo. 
- Considera el diseño del mural, pues debe tener elementos que llamen la atención y que inviten a participar de él; lo más recomendable para ello es usar fotos de las niñas y los niños dentro de sus salas. Así mismo, se debe cuidar que el mural no esté muy saturado de texto ni muy austero visualmente.

- Los murales interactivos son una estrategia muy útil y creativa, sin embargo, se recomienda que para mejores resultados vaya acompañado de contacto personal, es decir, necesitamos promover el mural acercándonos a las familias, explicándoles qué es y para qué sirve e invitándolas a participar en él. 


\section{Mensajes}

Permiten transmitir información breve. Se trata de una nota que elabora la educadora acerca de una situación que quiere compartir con una familia en particular; es un medio que permite mantener un acercamiento individualizado (ejemplo en anexo 10).

Objetivo: Establecer y mantener relaciones individualizadas con las familias de los niños y las niñas de su grupo.

\section{Características:}

- Son escritos breves que permiten compartir información relevante sobre algún niño o niña.

- Contienen información particular de lo que la educadora ha observado de un niño o niña en particular en el centro educativo.

- Permiten mantener informadas a las familias y hacerles sentir que su hijo/a es importante.

\section{Cómo elaborarlos:}

- Elige un día para escribir y enviar mensajes a las familias de tu sala.

- Piensa en una niño o niña de tu sala y en una pequeña hoja escribe un suceso o momento significativo que haya sucedido durante la semana; los mensajes pueden ser breves, pero significativos.

- Envía el mensaje por medio de la pañalera, mochila, tablero de comunicación o buzón.

- Pregunta de manera personal si recibieron el mensaje.

- Incluye a todas las familias de los niños y las niñas a tu cargo. Puedes partir de un formato sencillo que permita tener este tipo de acercamiento y que se convierta en un elemento de comunicación semanal.

- Invita a las familias a que compartan también, por escrito, algún momento significativo del fin de semana. 


\section{Buzón}

El buzón es una estrategia que permite mantener comunicación con las familias. Por este medio es posible intercambiar información que tanto las familias como las educadoras consideran importante para la atención de los/as niños/as (ejemplo en anexo 11).

\section{Características:}

- Es un espacio diseñado para el intercambio periódico de información entre la familia y la educadora.

- Están organizados por grupo, de tal manera que es sencillo para las familias saber en dónde se encuentra el espacio para compartir información con la educadora

- Cada familia tiene asignado un espacio en el cual puede colocar información que solamente leerá la educadora a cargo de su hijo/a.

\section{Objetivo:}

Promover y mantener la comunicación entre la educadora y las familias de los niños y niñas de la sala.

\section{Cómo elaborarlo:}

- Coloca un tablero, con espacios o compartimentos para cada familia de los niños y niñas de tu sala, que contenga el nombre de cada uno y que esté a la vista de las familias.

- Asigna un día para escribir algún mensaje a cada familia de tu sala.

- Escribe en una hoja un avance, logro o anécdota de cada niño y niña.

- Coloca los mensajes en los espacios correspondientes del tablero.

- Explica de forma individual a las familias el objetivo del buzón.

- Invita a las familias a participar escribiendo mensajes y depositándolos en el buzón. 


\section{Diario}

Es una herramienta de gran utilidad para el trabajo día a día. Puede tener diversas formas; la más frecuente es utilizar un cuaderno pequeño para cada niño/a, personalizado con su nombre, y si es posible, una fotografía.

La realización de un diario es de gran utilidad para documentar el proceso de aprendizaje de las niñas y los niños, pues al realizarse de manera cotidiana da cuenta de los diferentes momentos por los que atraviesan y las estrategias que como educadoras y familia usamos para apoyarlas/os (ejemplo en anexo 12).

Objetivo: Establecer y mantener comunicación con las familias a través del intercambio de información.

\section{Características:}

- Es una herramienta que permite establecer comunicación constante entre la familia y el centro educativo porque abre una puerta para que tanto la educadora como los miembros de la familia pueden compartir eventos que ocurren en el salón o la casa y que son significativos para el niño o la niña.

- Está compuesto por notas que transmiten mensajes acerca del niño/a; permite tener mayor conocimiento de quien es él/ella en el "otro" espacio (la casa para la educadora; la escuela para las familias).

- Permite documentar el proceso de aprendizaje de las niñas y los niños, pues al realizarse de manera cotidiana da cuenta de los diferentes momentos por los que atraviesan y las estrategias que como educadoras y familias utilizan para apoyarlas/os.

\section{Cómo elaborarlo:}

- Asigna un cuaderno para llevar a cabo el diario.

- Comenta con las familias que no es una libreta de quejas sino una herramienta valiosa para que los miembros de la familia y las educadoras estén al tanto de lo que aprende y hace el/la niño/a.

- Realiza observaciones al menos una vez a la semana que te permitan elaborar notas de los logros de los niños y niñas para compartir con las familias.

- Asigna un día para elaborar esas notas y hacérsela llegar a las familias.

- Invita a las familias a compartir experiencias. 


\section{Circulares informativas}

Son medios utilizados para informar a las familias de algún evento que se llevará a cabo en el centro educativo. Se llama "circular" ya que solicita información de vuelta, como por ejemplo el nombre de la persona asistente, que indique si asistirá o no, etc. (ejemplo en anexo 13).

Objetivo: Invitar e informar a las familias acerca de un evento escolar.

\section{Características:}

- Son una especie de carta invitación en donde se informa a las familias de un evento específico que se llevará a cabo en el centro educativo.

- Contienen dos partes:

1. Informa acerca del evento, indicando el motivo del mismo, sus objetivos e información básica acerca de fecha, horario y lugar.

2. Espacio para confirmar su asistencia y participación, en donde se solicita información del participante. Debe ser devuelto al personal del centro educativo.

- Permiten prever el número aproximado de personas que asistirá al evento.

\section{Cómo elaborar:}

- Escribe a quién va dirigida la invitación.

- Explica el objetivo de la actividad a la cual los estás invitando, señalando el motivo de su realización.

- Indica la fecha, hora y lugar de la actividad.

- Indica quién organiza el evento y quién es el responsable del mismo.

- Deja un espacio para que las familias respondan, solicitando que devuelvan el volante; en este espacio vuelve a poner de qué evento se trata y solicita la información necesaria para su registro. Algunos datos que se solicitan normalmente son:

- $\quad$ Nombre del padre/madre participante

- Nombre de su hijo/a y/o sala/grupo

- Que indique si asistirá o no

Sin embargo, puedes solicitar la información que te sea de mayor utilidad, tomando en cuenta que el espacio es reducido.

- Revisa la circular antes de distribuirla, asegurándote de que contiene la información necesaria que permitirá a las familias comprender de qué evento se trata y decidir su asistencia.

$-30-$

Construyendo Comunidades de Aprendizaje: Un Programa de Formación de Educadoras de niños y niñas de o a 6 años. Estrategias de vinculación entre la Familia y la Escuela. Rosa Nashiki, Roxanna Pastor, Miguel Pérez, Rocío Hernández, Leticia Lemus y Carla Ocón. 


\section{Evaluación de las estrategias empleadas}

Se recomienda evaluar la utilidad de las estrategias inmediatamente después de realizarlas, ya que la respuesta de las familias es más fidedigna al tener esta experiencia presente; además, esto permite conocer oportunamente la opinión de las familias y la utilidad de la estrategia para la realización de ajustes o modificaciones.

Para llevar a cabo la evaluación de este tipo de estrategias es necesario que se utilicen cuestionarios de evaluación que consideren la obtención de información específica acerca de las acciones que se desarrollaron.

Para el caso de los encuentros personales se sugiere el uso del siguiente cuestionario de evaluación (anexo 14 para fotocopiar):

Nombre del madre/padre:

Grupo: Fecha de evaluación:

\section{Cuestionario de evaluación de encuentros personales}

El presente instrumento tiene como finalidad evaluar la utilidad de los materiales y los contenidos de los mismos. Por favor comente acerca de:

1. ¿Qué aprendió acerca de su hijo/a?

2. ¿Qué aprendió acerca de la educadora?

3. ¿Qué aprendió acerca de lo que su hijo/a hace?

4. En una escala del 1 al 5 , en donde uno es lo menos y cinco lo más:

a) ¿qué tanto fueron escuchadas sus dudas, inquietudes y necesidades? ¿Por qué?

b) ¿qué tan útiles son las sugerencias o alternativas que le brindaron para apoyar a su hijo/a? ¿Por qué?

5. ¿Volvería a participar en una actividad similar? ¿Por qué?

6. Comentarios adicionales:

El principal objetivo de este cuestionario es conocer la utilidad de la estrategia así como el impacto en el establecimiento de la relación entre la educadora y las familias; también es útil para decidir las acciones a llevar a cabo con el fin de generar condiciones que promuevan la participación de las familias. 
En cuanto a la evaluación de los materiales impresos se recomienda el siguiente cuestionario a partir del cual es posible identificar los ajustes que será necesario realizar (ver anexo 15, versión para fotocopiar).

Nombre de la madre/padre:

Grupo: Fecha de evaluación:

\section{Cuestionario de evaluación de materiales impresos}

El presente instrumento tiene como finalidad evaluar la utilidad de los materiales y los contenidos de los mismos.

1. ¿Cómo se relaciona el tema con lo que le está ocurriendo a su hijo/a?

2. ¿Para qué le fue útil la información proporcionada?

3. ¿Qué tan útiles fueron las sugerencias que se le brindaron? ¿Por qué?

4. ¿Cómo el material elaborado le permitió acercarse a la educadora?

Comentarios adicionales:

Una vez recabada la información es necesario analizarla y realizar los ajustes necesarios para favorecer la participación de las familias a través del uso de las estrategias implementadas. Cabe resaltar que la participación de las familias se logra con el empleo de más de una estrategia de manera simultánea, de tal manera que entre más medios se tengan para propiciar la comunicación con las familias y para hacerles sentir valoradas, mayor cercanía establecerán con las educadoras. 


\section{Bibliografía}

Benson, F. \& Martin, S. (2003). "Orginizing Successful Parent Involvement in Urban Schools". Child Study Journal, vol. 33, núm. 3, pp. 87-193.

Brunson, C. (1991). Fundamentos para asociados en desarrollo infantil que trabajan con niños pequeños. Washington, D.C.: Council for Professional Recognition.

口] Cataldo, C. (1991). Aprendiendo a ser padres. Conceptos y contenidos para el diseño de programas de formación de padres. Madrid: Visor Distribuciones, cap. 1, pp. 28-41.

[Da Christie, K. (2005). "Changing the Nature of Parent Involvement". Phi Delta Kappa, mayo, vol. 86, núm 9, pp. 645-646.

Copple, C. (2006). Basics of Developmentally Appropriate Practice. Washington, D.C.: NAEYC.

Cunningham, C. \& Davis, H. (1988). Trabajar con los padres. México: Siglo XXI.

Dichtelmiller, M. \& Ensler, L. (2004). "Infant/Toddler Assessment: One Program's Experience", en D. Koralek (ed.), en Spotling on Young Children and Assessment. Washington D.C.: NAEYC.

Gronlund G. y Engel, B. (2001). Focused Portfolios. A Complete Assessment for the Young Child. St. Paul, Canada: Redleaf Prees.

Hammer, T. \& Tunner, P. (2001). Parenting in Contemporary Society. Boston: Allyn and Bacon.

Hohmann, M. (1999). La educación de los niños pequeños en acción: manual para profesionales de la educación infantil. México: Trillas.

[1] Hyson, M. \& Olson, M. (2003). Early Childhood Educators and Child Abuse Prevention: Perspective, Findings, Actions. 3. The NAEYC Perspective on Research Program. www.naeyc.org (recuperado el 8/08/05).

[1] Kaczmarec, L. (2007). A Team Approach. Spoting on young children and families Washington D.C.: NAEYC.

[D Keyser, J. (2006). From Parents to Partners. Building a family-centered early childhood program. St. Paul, Canada: Redleaf Press.

Klass, C. (2003). The Home Visitor's: Guidebook. Baltimore: Paulh Brookes Publishing Co.

Meisels, S., Mariden, D., Dombro, A. \& Dichtelmiller, M. (2003). The Once Scale. Nueva York: Pearson Early Learning.

Million, J. (2003). "Talking to Parents". Education Digests, enero, vol. 68, núm. 5, pp. 52-53. 
[a] Nashiki, R. (2006). La participación de las familias en centros de educación infantil: una propuesta desde los retos del desarrollo. Tesis de Maestría, México: UNAM-Facultad de Psicología.

ㅁal Pérez, M. (2008). Programa de Transición del Preescolar al Primer grado: manual de implementación. México: UNAM-Facultad de Psicología.

미 Riley, R. (1998). Early Childhood Conference in Atlanta Georgia. September 11, 1998. Remarks as Prepared for Delivery by U.S. Secretary of Education Richard W. Riley. Washington, D.C.: Department of Education.

[L] Riojas-Cortez, M., Bustos, B. \& Riojas-Clark, E. (2003). "Valuing and Connecting Home Cultural Knowledge with an Early Childhood Program". Journal Young Children on Web, November 2003.

메 Shores, E. (1998). A Call to Action: Family involvement as a critical component of teacher education programs. Tallahassee, Florida USA: SERVE.

[Da Stacey, M. (1996). Padres y maestros en equipo: trabajo conjunto para la educación infantil. México: Trillas.

@ Tovar, I. (2006). Un currículo para niños/as lactantes: los momentos asistenciales como oportunidades de aprendizaje. Tesis de Maestría. México: UNAM-Facultad de Psicología. 
Anexos 


\section{Encuentros espontáneos}

Un encuentro espontáneo que permite dialogar con las familias es cuando van a recoger a su hijo/a para llevarlo a una cita médica. Este permite tener mayor cercanía con cada familia y conocer más a cada niño/a.
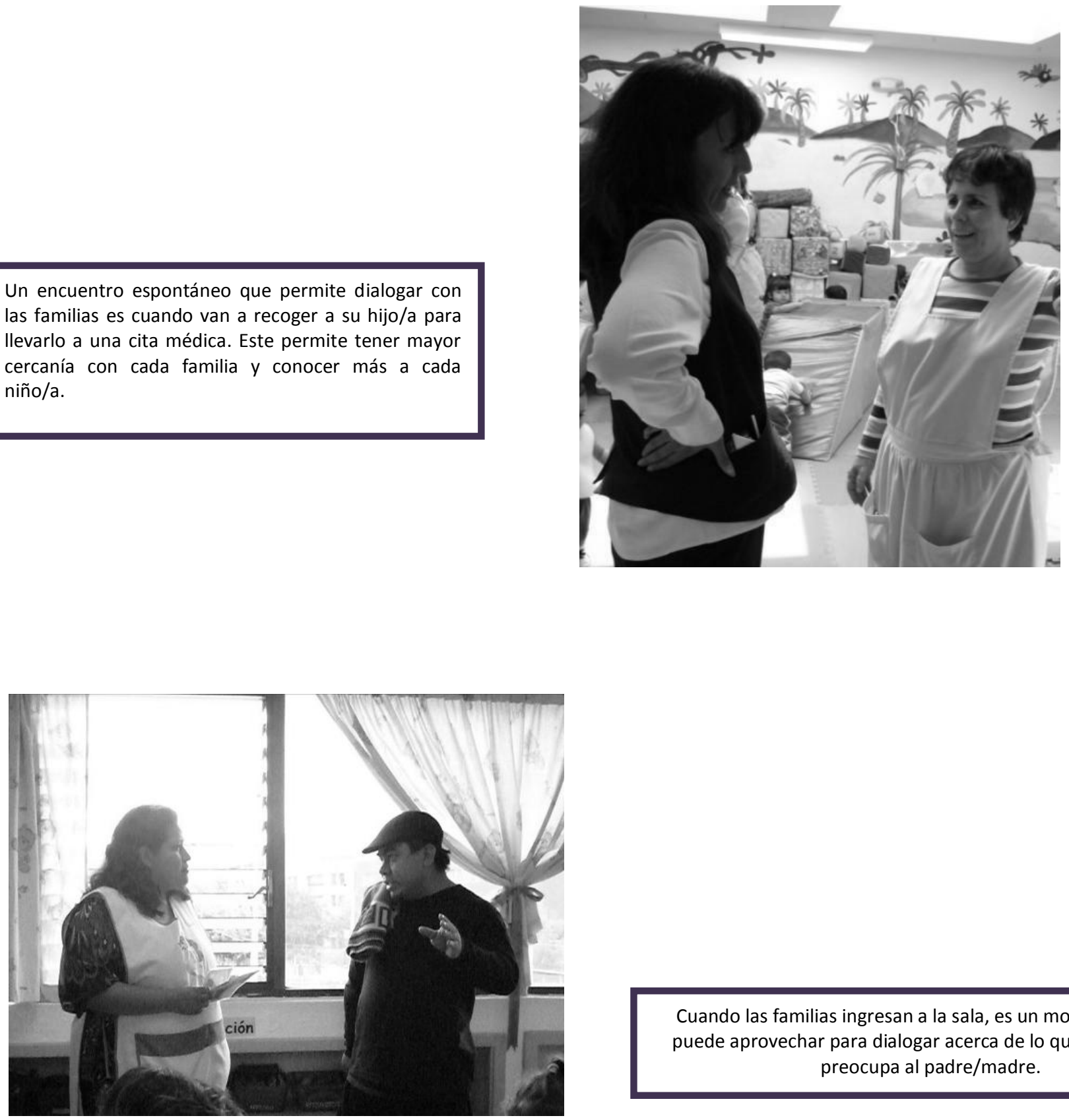

Cuando las familias ingresan a la sala, es un momento que se puede aprovechar para dialogar acerca de lo que le interesa o preocupa al padre/madre.

-36-

Construyendo Comunidades de Aprendizaje: Un Programa de Formación de Educadoras de niños y niñas de o a 6 años. Estrategias de vinculación entre la Familia y la Escuela. Rosa Nashiki, Roxanna Pastor, Miguel Pérez, Rocío Hernández, Leticia Lemus y Carla Ocón. 


\section{Juntas informativas}

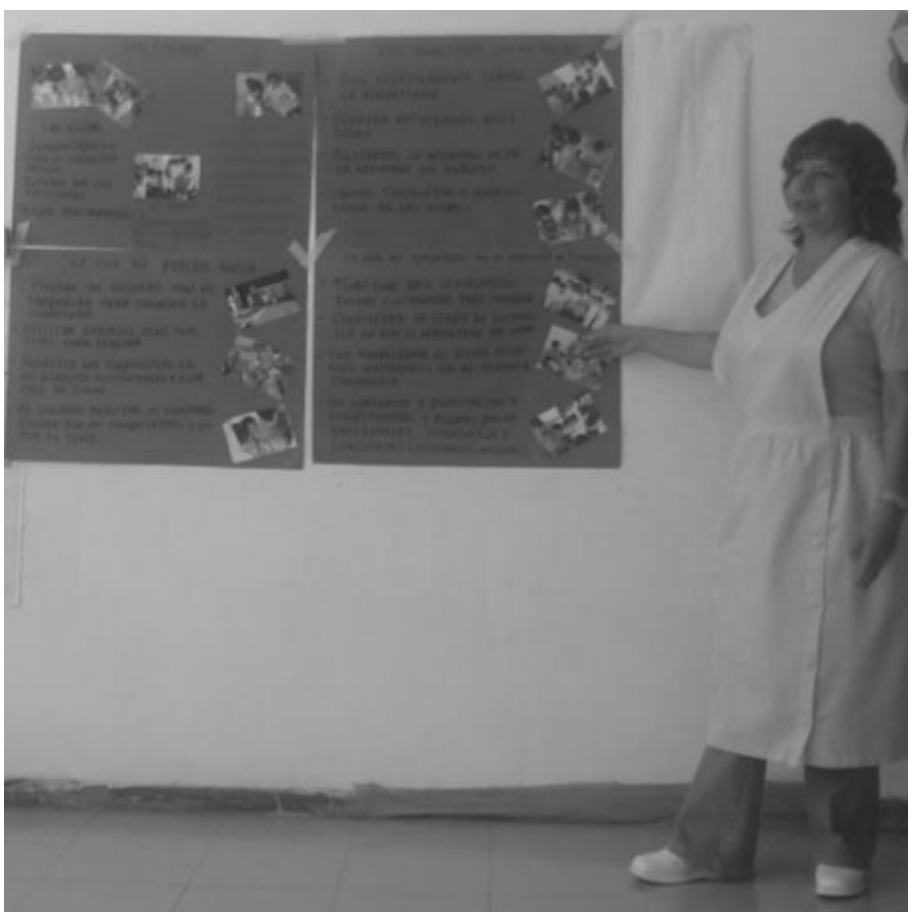

Una junta informativa con imágenes de los niños/as de la sala que representen los principales logros y retos del grupo permite que las familias comprendan mejor la situación del grupo y tener un tema en común para el diálogo.

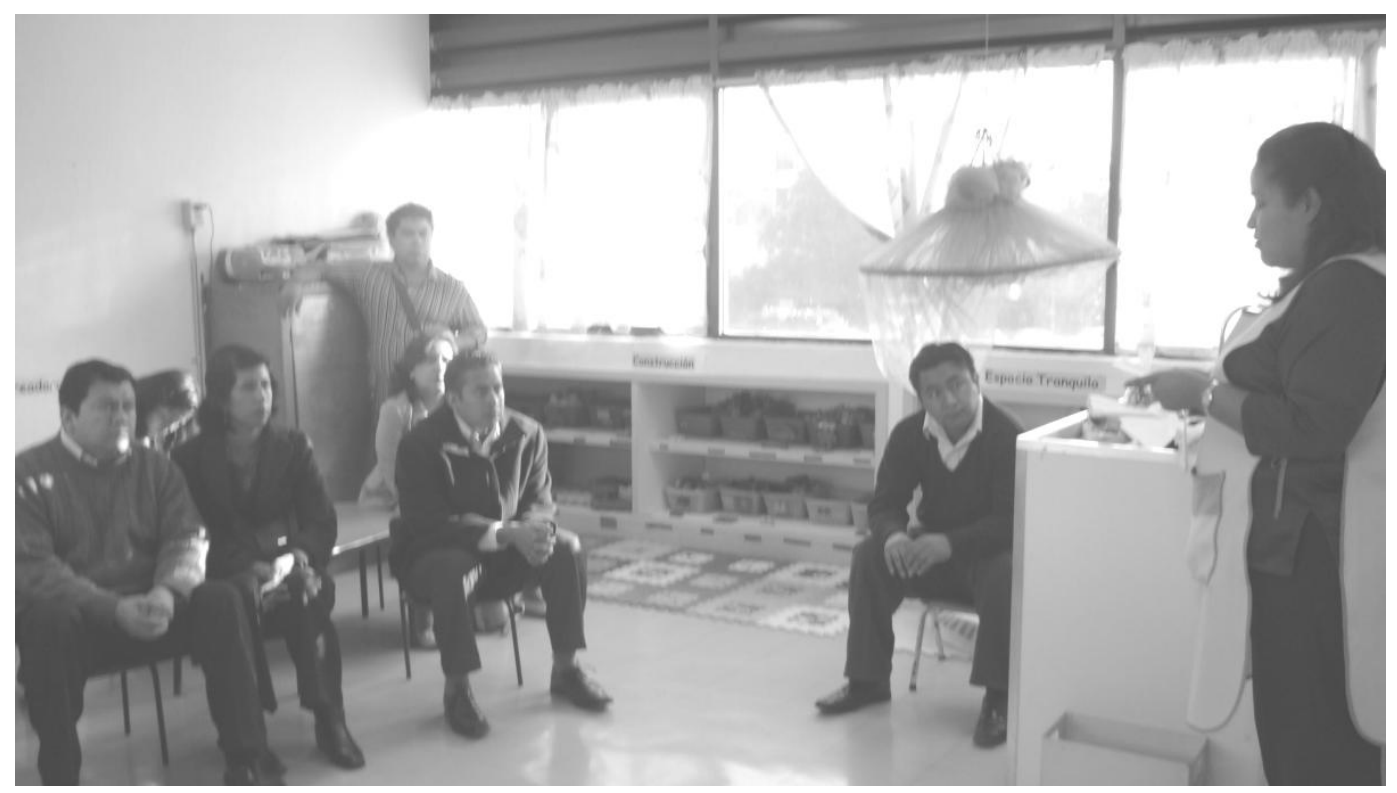

Preparar el espacio para recibir a las madres y padres permite dialogar de manera directa con cada persona. 


\section{Visita a sala}

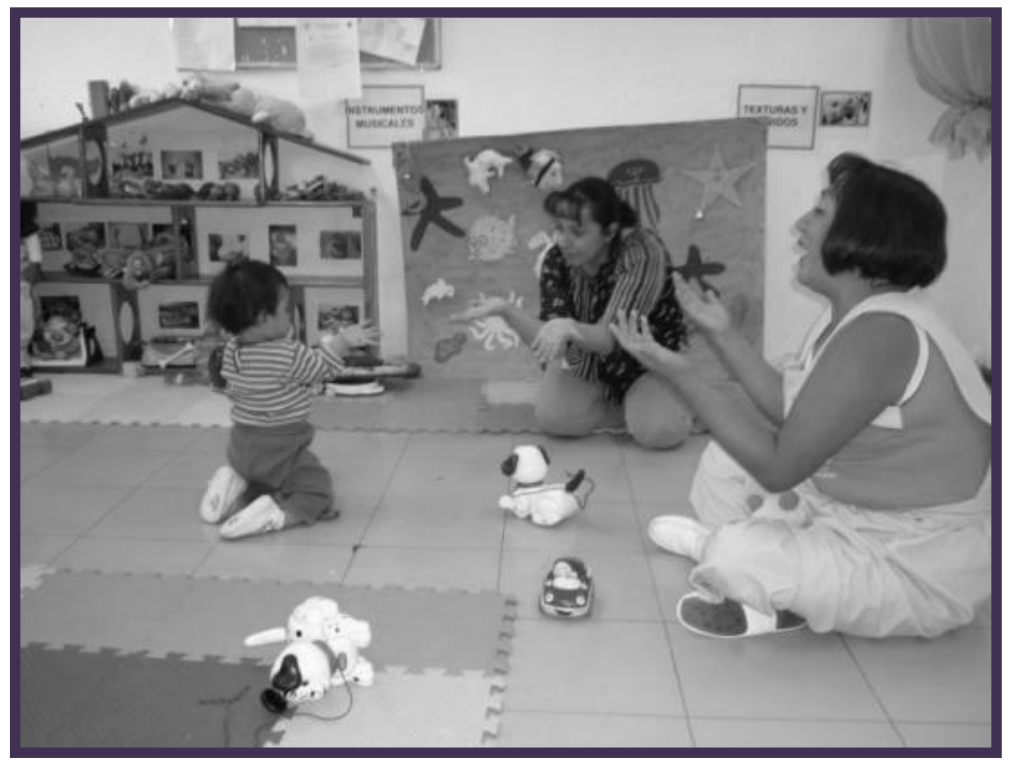

Cuando las familias visitan la sala, conocemos mejor lo que pasa en casa.

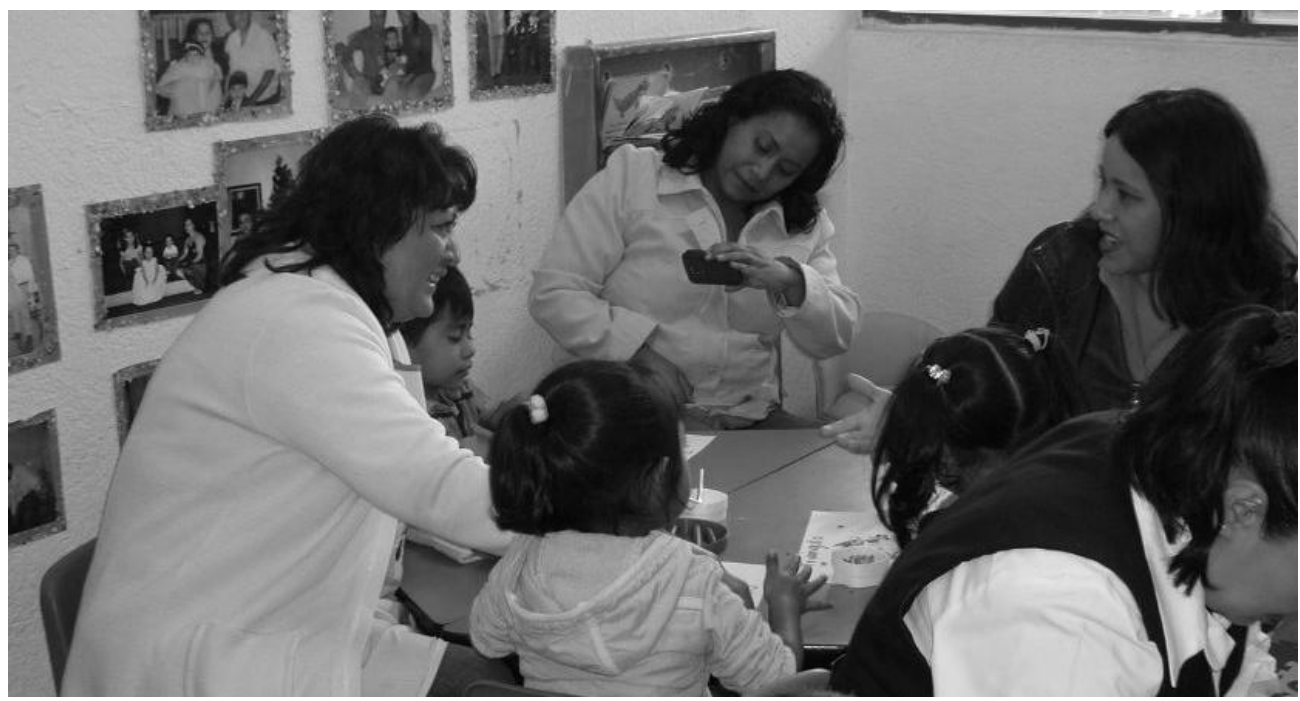

Cuando las familias visitan la sala, son oportunidades para dialogar acerca de lo que puede hacer su hija/o, sus logros y retos.

Construyendo Comunidades de Aprendizaje: Un Programa de Formación de Educadoras de niños y niñas de o a 6 años. Estrategias de vinculación entre la Familia y la Escuela. Rosa Nashiki, Roxanna Pastor, Miguel Pérez, Rocío Hernández, Leticia Lemus y Carla Ocón. 


\section{Proyectos de trabajo}

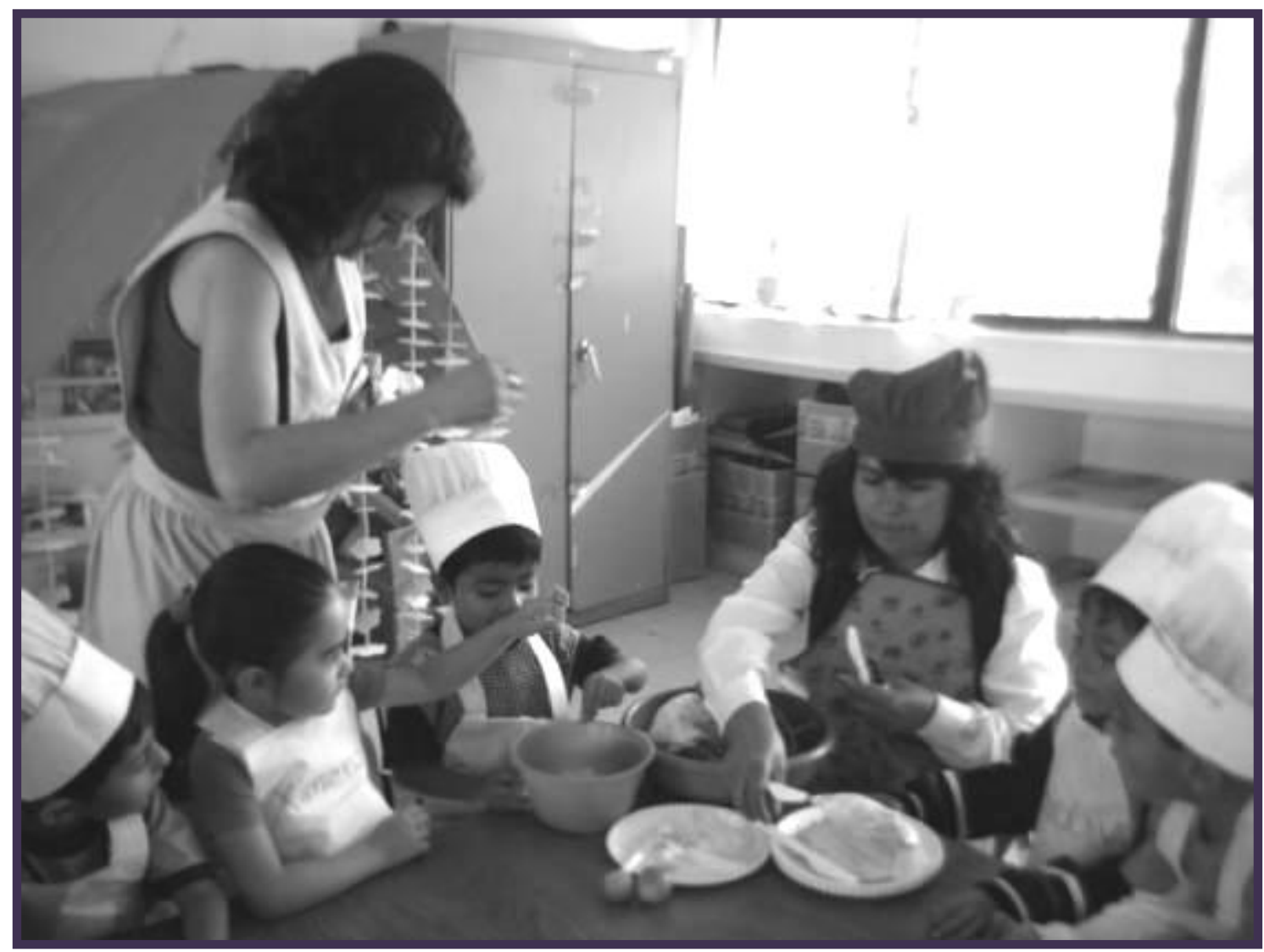

Cocinando dentro de las salas las familias, las niñas, los niños y las maestras nos conocemos mejor. 


\section{Visitas domiciliarias}

\section{Habilidades de un/a visitador/a}

De acuerdo con Klass (2003), el visitador o visitadora debe poseer las siguientes habilidades que le permitan establecer y mantener una relación con las familias.

- Dar atención individualizada. Reconocer que cada familia es única. Una forma de individualizar su labor es dirigirse a cada familia de acuerdo a sus costumbres, valores, normas de conducta, rutina y prioridades. Cuando el visitador/a entiende esto es capaz de usar sus habilidades de observación y comunicación para guiar y apoyar a la familia.

- Establecer respeto y rapport. En toda relación es necesario establecer momentos que generen un ambiente de confianza y cordialidad. Esto inicia en el momento en que el/la visitador/a es capaz de valorar y aceptar a la familia. Comunicar su aceptación se logra a través del respeto y una sincera aceptación.

- Escuchar y apoyar con empatía. Se lleva a cabo al intentar ver las cosas desde la perspectiva de las familias, reconociendo sus sentimientos, como una manera de brindar el apoyo que necesitan, comunicarles que se les entiende y valorar lo que están compartiendo.

- Escuchar activamente: retroalimentar. Significa hacerle ver al padre/madre que se le escucha y atiende a lo que dice; algunas formas de hacerlo son parafraseando lo que dice, repetir uno de los comentarios o hacer ademanes o exclamaciones positivos de lo que está comentando.

- Observar y afirmar. Una de las principales habilidades es la observación, ya que a través de ella el/la visitador/a conoce a la familia, realiza comentarios de manera oportuna y ajusta sus interacciones de acuerdo a lo que está ocurriendo. Esta habilidad incluye tanto la observación como la capacidad de comunicarle a la familia lo que puede hacer, es decir, la visitadora debe ser capaz de comentar y reconocer lo que la familia hace de manera positiva, reconociendo y apoyando sus fortalezas (lo cual contribuye a que tengan confianza en sí mismos y disminuyan cualquier sentimiento de incomodidad) y ajustar sus interacciones con la familia.

- Modelar. Significa poder realizar acciones que los padres puedan imitar y llevar a cabo de manera independiente, para lo cual el/la visitador/a necesita tener en mente qué es lo que desea que la familia realice y en algunas ocasiones llevar a cabo actividades planeadas para ello.

- Compartir información sobre el desarrollo. Una de las tareas centrales es proporcionar información sobre el desarrollo del niño/a y las prácticas parentales apropiadas. Esto tiene un mejor efecto cuando se hace a partir de las observaciones realizadas con un lenguaje sencillo.

- Hacer interpretaciones del desarrollo. El/la visitador/a puede explicar la importancia de una conducta del desarrollo, resaltando las razones por las cuales las lleva a cabo. Esto permite generar las condiciones necesarias para que la familia pueda promoverlo.

$-40-$

Construyendo Comunidades de Aprendizaje: Un Programa de Formación de Educadoras de niños y niñas de o a 6 años. Estrategias de vinculación entre la Familia y la Escuela. Rosa Nashiki, Roxanna Pastor, Miguel Pérez, Rocío Hernández, Leticia Lemus y Carla Ocón. 
- Ofrecer sugerencias en el momento. Consiste en brindar sugerencias directas acerca de algo que esté ocurriendo; así el mensaje que se trasmita en el momento de la visita influirá directamente en su relación y en la efectividad del proceso.

- Hacer preguntas. Las preguntas son una parte natural de una conversación; es necesario que éstas sean abiertas, de tal manera que permitan que la conversación fluya. Se pueden hacer preguntas para asegurarse de que se está entendiendo lo que el padre o la madre están expresando, o para pedir que den un ejemplo o para conocer el significado de alguna palabra. En ocasiones una pregunta puede ayudar a enfocar un problema específico.

- Resolver problemas. Ayudar a la madre/padre a resolver problemas así como a darse cuenta de que algunas de sus acciones son (o no) apropiadas. Una manera de que se dé esto es proporcionar información del desarrollo, brindar sugerencias e invitar a que cada persona comparta su punto de vista o su comprensión del problema. Algunas preguntas pueden ayudar al padre/madre a mirar el problema desde una perspectiva diferente.

- Promover la participación activa. Durante la visita se espera que el padre/madre interactúe de manera directa con su hijo/a, pero de no darse de manera espontánea el visitador debe generar las condiciones para que esto ocurra, ya sea invitándolo/a a participar o bien pidiéndole que lea un cuento.

- Sentirse a gusto con el silencio. Con la experiencia, el/la visitador/a aprende a mostrarse relajada/o y a gusto con la compañía de la madre/padre en su hogar. Generalmente los momentos de silencio se dan cuando el padre/madre y el/la visitador/a observan al niño/a. Durante estos tiempos a menudo el padre o la madre hace comentarios de los logros o situaciones observadas en visitas anteriores que pueden ser reafirmados por el/la visitador/a.

- Equilibrio en la interacción. Las visitas necesitan estar equilibradas en cuanto a las interacciones con ambos padres y con los/as niños/as. Realizar las visitas involucra tareas múltiples, como discutir aspectos del desarrollo y las habilidades que va adquiriendo el/la niño/a, las prácticas parentales y los problemas. Ello implica que el/la visitador/a considere previamente las actividades para cada una de las visitas y que tenga en mente cómo va a involucrar a la madre/padre en estas actividades. 


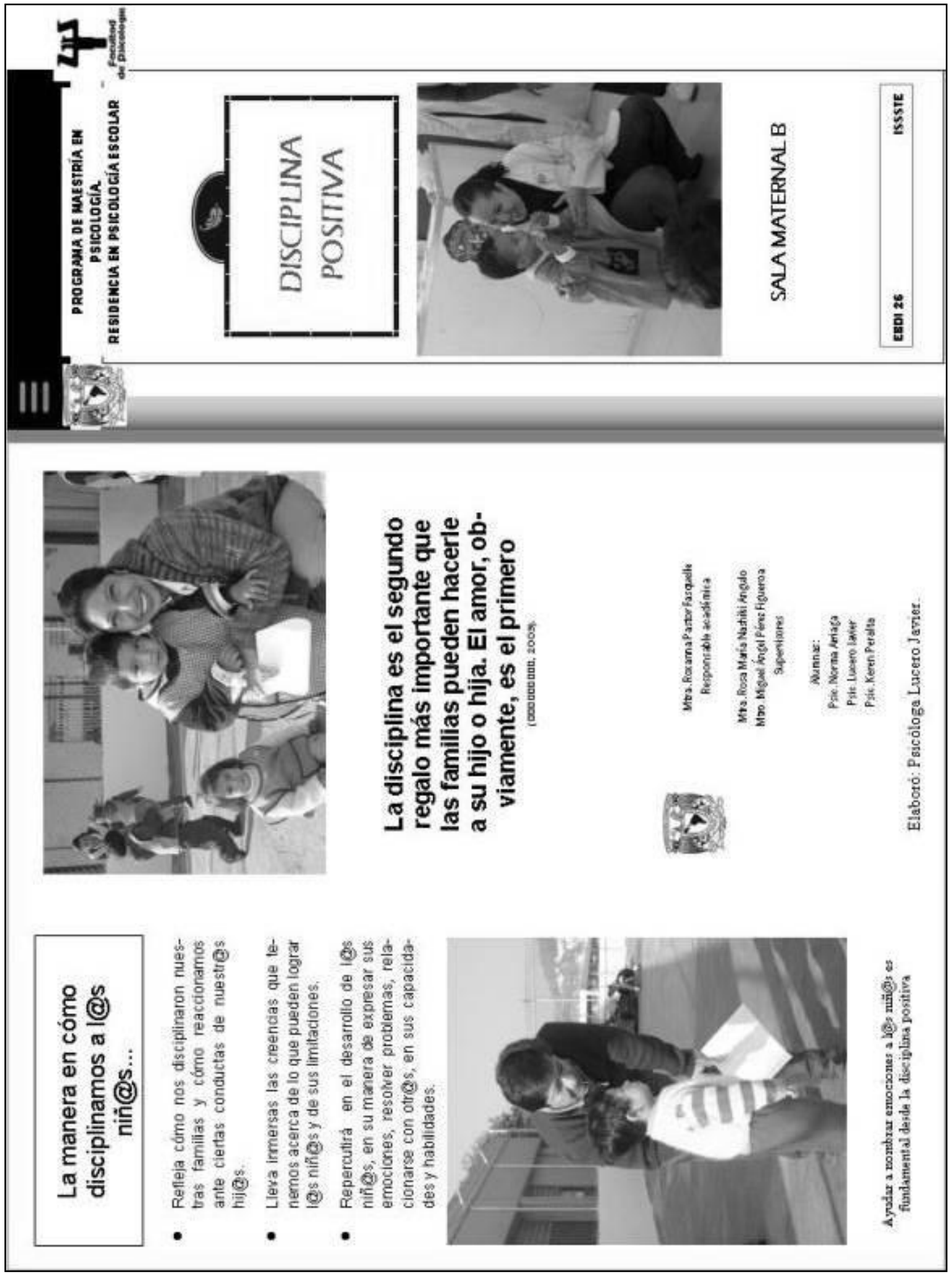

$-42-$

Construyendo Comunidades de Aprendizaje: Un Programa de Formación de Educadoras de niños y niñas de o a 6 años. Estrategias de vinculación entre la Familia y la Escuela. Rosa Nashiki, Roxanna Pastor, Miguel Pérez, Rocío Hernández, Leticia Lemus y Carla Ocón. 
Anexo 6

Tríptico

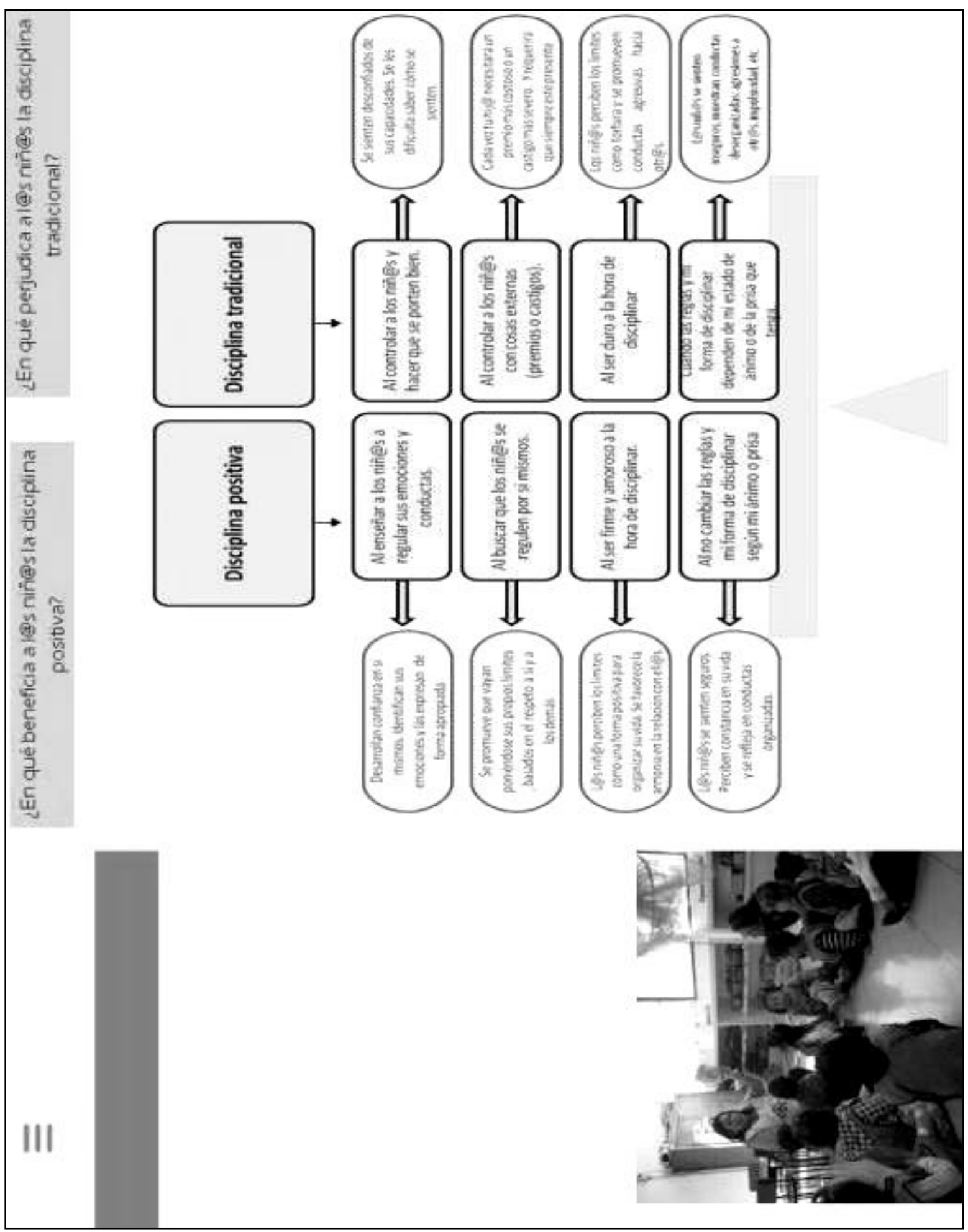




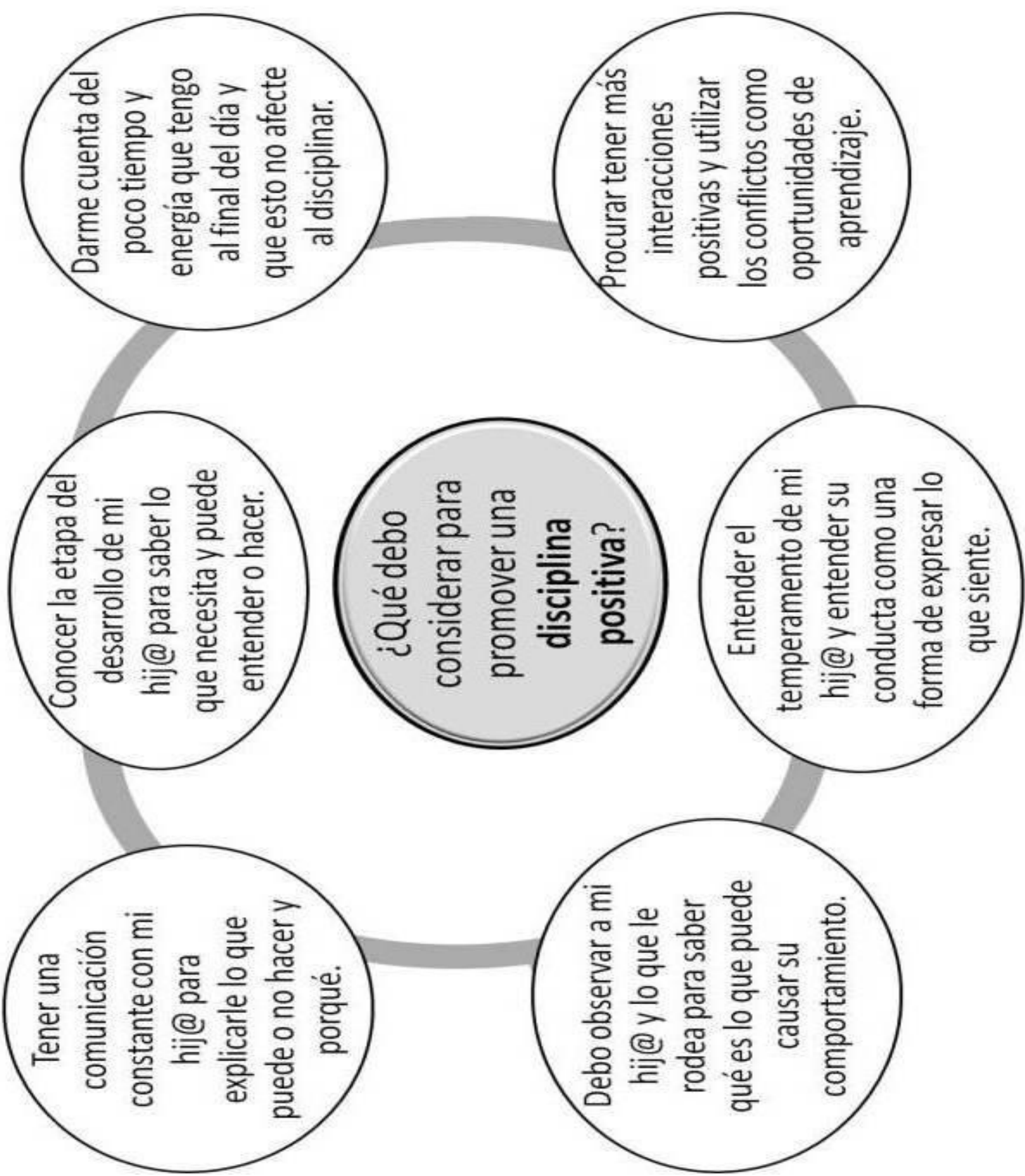

$-44-$

Construyendo Comunidades de Aprendizaje: Un Programa de Formación de Educadoras de niños y niñas de o a 6 años. Estrategias de vinculación entre la Familia y la Escuela. Rosa Nashiki, Roxanna Pastor, Miguel Pérez, Rocío Hernández, Leticia Lemus y Carla Ocón. 


\section{Fotografía de habilidades}

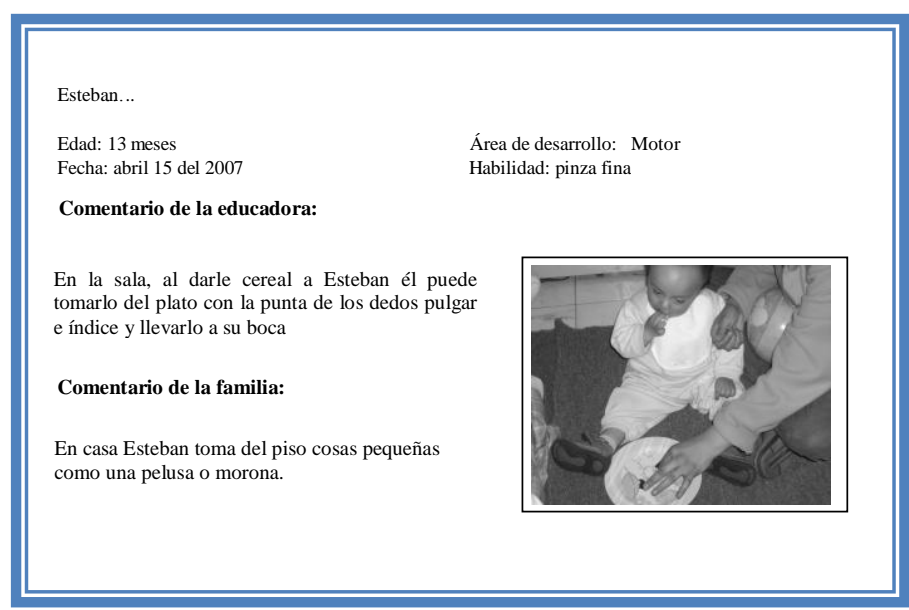

\section{Cartulina de sugerencias}

\section{Familias:}

Dentro de sala durante esta sem ana trabajam os de m anera conjunta para apoyary prom over el desarrolloy y prendizaje desu hij@ durantelas diferentes actividades que planeam os. Considerando los m om entos asistenciales com o oportunidades de aprendizaje y queremos compartir con ustedes algunos ejemplos de cómo lo hacem os.

\begin{tabular}{|c|c|}
\hline Mbmento & Sugerencias \\
\hline Aimentación & $\begin{array}{l}\text { Ponerse a su nivel y decirle "vamos a comer sopa" } \\
\text { - Invitar@ a que se siente a la mesa con todos los } \\
\text { miembros de la familia. } \\
\text { Permitirle que em plee la cuchara para comer. } \\
\text { Aunque esto implique en ocasiones que se ensucie su ropa. } \\
\text { Evite darle de com er en la boca. } \\
\text { Apoyarl@ colocándole la cuchara en su mano y silo } \\
\text { requiere, guíarsu mano del plato a suboca. }\end{array}$ \\
\hline
\end{tabular}

Atentamente: Maestra Karen 


\section{Mural}

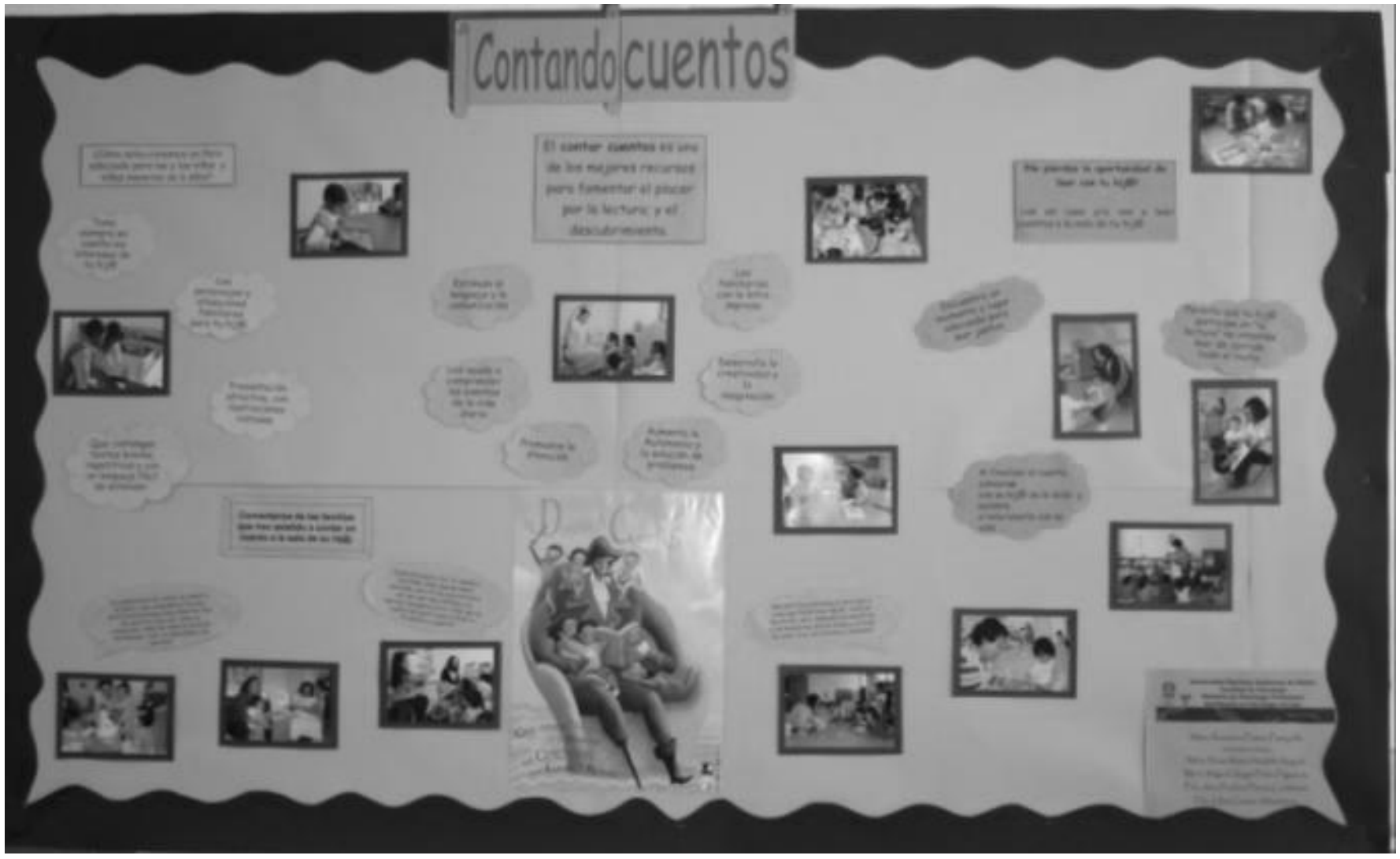

\section{Murales interactivos}
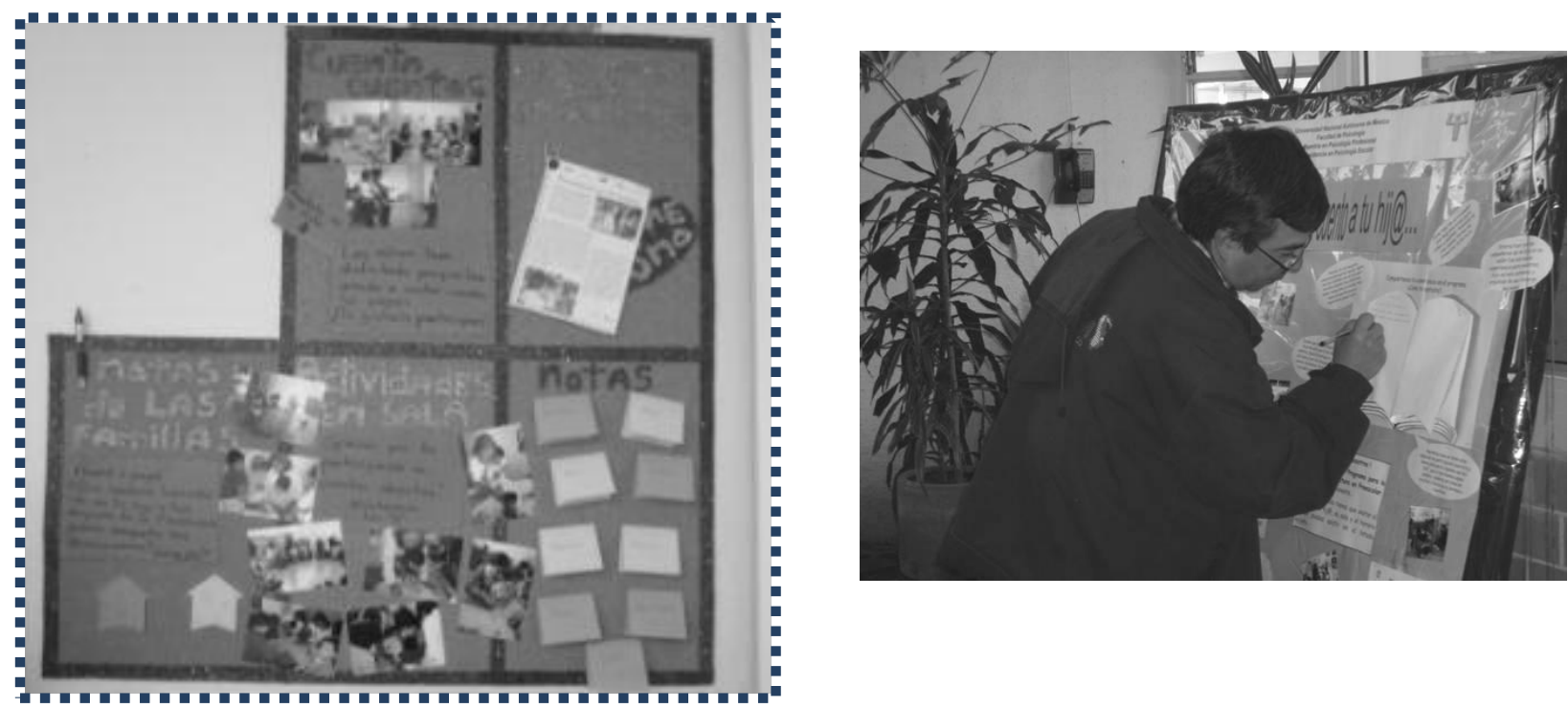

$-46-$

Construyendo Comunidades de Aprendizaje: Un Programa de Formación de Educadoras de niños y niñas de o a 6 años. Estrategias de vinculación entre la Familia y la Escuela. Rosa Nashiki, Roxanna Pastor, Miguel Pérez, Rocío Hernández, Leticia Lemus y Carla Ocón. 

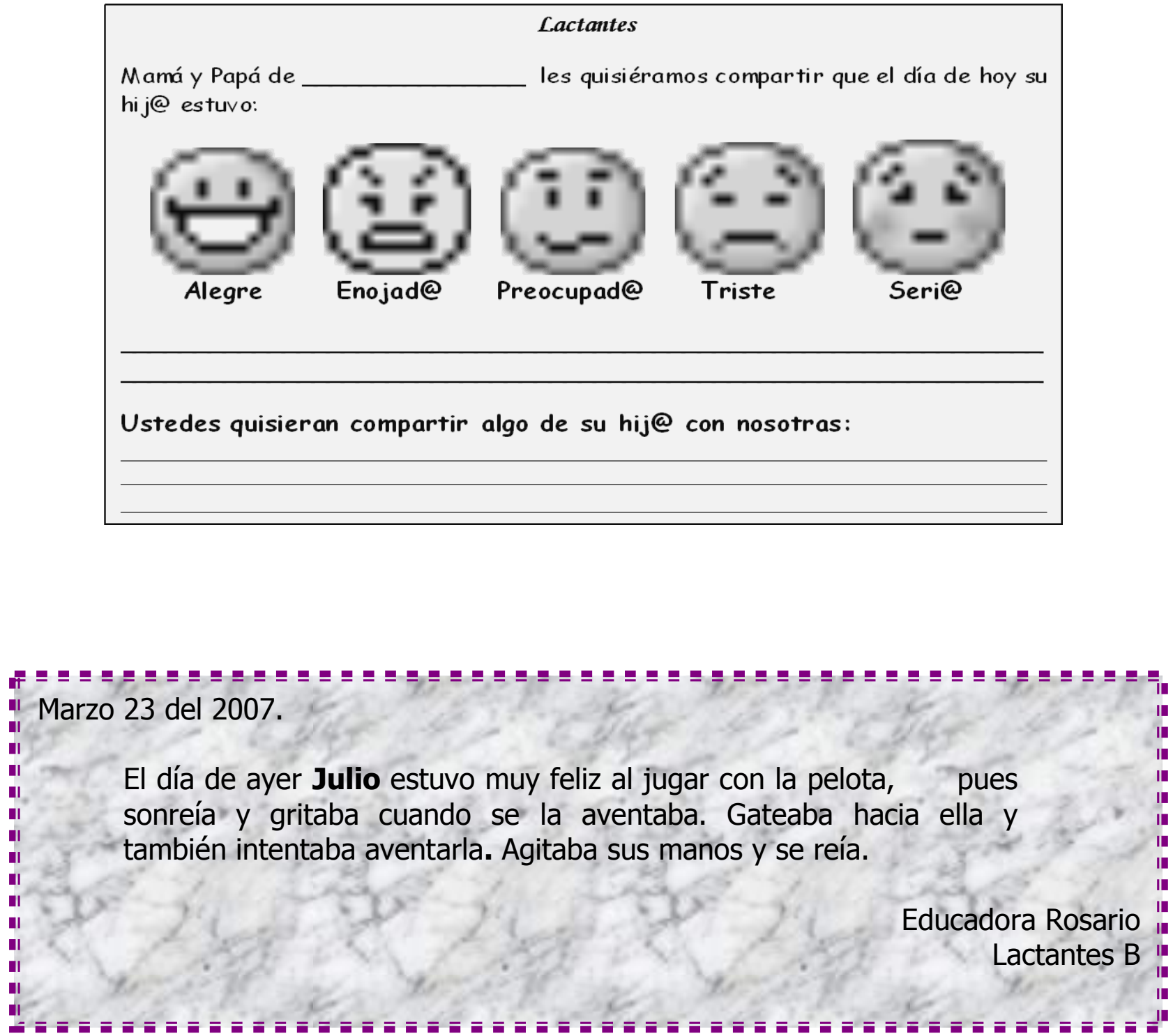


\section{Buzón}

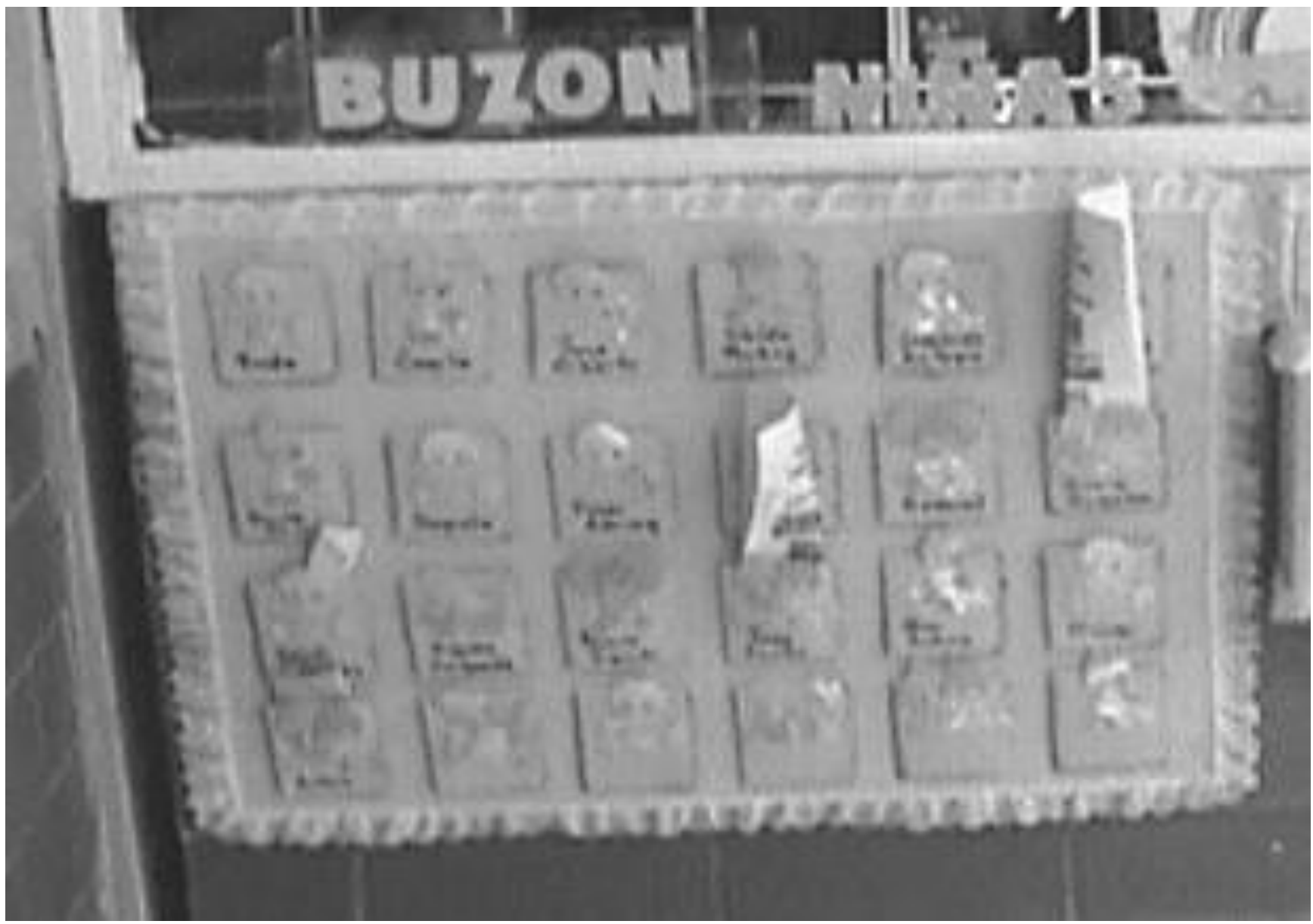

$-48-$

Construyendo Comunidades de Aprendizaje: Un Programa de Formación de Educadoras de niños y niñas de o a 6 años. Estrategias de vinculación entre la Familia y la Escuela. Rosa Nashiki, Roxanna Pastor, Miguel Pérez, Rocío Hernández, Leticia Lemus y Carla Ocón. 
- Esta mañana cuando servía el agua, Héctor se acerco a mi, extendió su brazo, señalado la jarra del agua y dijo "ahua". Algo que me dio mucho gusto, pues yo he promovido durante estas últimas semanas que Héctor tenga que pedir las cosas en lugar de adivinar su pensamiento y darle el agua, antes de que el lo pida.

Maestra Susana

\section{2 de marzo de 2006}

"El día hoy, por primera vez Raúl se acercó a su prima y la invitó a armar un rompecabezas juntos. Al principio les costó trabajo jugar juntos pero al final se pusieron de acuerdo.

Fue un muy buen día para ambos."

Saludos cordiales,

Sra. Alicia 
Estimadas familias:

Como parte del proyecto "cuidemos nuestra escuela" durante el mes de abril se estarán elaborando juguetes con material de reuso en las salas de los niños y las niñas preescolares.

Se les invita cordialmente a asistir a la sala de su hijo/a a elaborar un juguete con él/ella del 18 al 22 de abril.

Favor de responder y devolver el talón adjunto especificando si desea participar en la actividad y el horario de su preferencia. Colocar su talón en el buzón de la sala.

Con aprecio,

Maestra Sara.

Nombre del niño/a:

Nombre de la madre/padre:

Deseo participar ( ) No deseo participar ( )

Horario de preferencia

\begin{tabular}{|c|l|c|c|c|c|}
\hline Hora/día & Lunes 18 & $\begin{array}{c}\text { Martes } \\
\mathbf{1 9}\end{array}$ & $\begin{array}{c}\text { Miércoles } \\
\mathbf{2 0}\end{array}$ & $\begin{array}{c}\text { Jueves } \\
\mathbf{2 1}\end{array}$ & $\begin{array}{c}\text { Viernes } \\
\mathbf{2 2}\end{array}$ \\
\hline $9: 00$ & & & & & \\
$\mathrm{a}$ & & & & & \\
$9: 30$ & & & & & \\
\hline $\begin{array}{c}11: 30 \\
a\end{array}$ & & & & & \\
$12: 00$ & & & & & \\
\hline
\end{tabular}

$-50-$

Construyendo Comunidades de Aprendizaje: Un Programa de Formación de Educadoras de niños y niñas de o a 6 años. Estrategias de vinculación entre la Familia y la Escuela. Rosa Nashiki, Roxanna Pastor, Miguel Pérez, Rocío Hernández, Leticia Lemus y Carla Ocón. 


\section{Cuestionario de evaluación de encuentros personales}

Nombre de madre/padre:

Sala:

Fecha de evaluación:

El presente instrumento tiene como finalidad evaluar la utilidad de los materiales y los contenidos de los mismos. Por favor comente acerca de:

1. ¿Qué aprendió acerca de su hijo/a?

2. ¿Qué aprendió acerca de la educadora?

3. ¿Qué aprendió acerca de lo que su hijo/a hace?

4. En una escala del 1 al 5, en donde uno es lo menos y cinco lo más:

a) ¿Qué tanto fueron escuchadas sus dudas, inquietudes y necesidades? ¿Por qué? 
b) ¿Qué tan útiles fueron las sugerencias se le brindaron para apoyar a su hijo/a)? ¿Por qué?

\begin{tabular}{l|l|l|l|l|}
$\mathbf{5}$ & $\mathbf{4}$ & $\mathbf{3}$ & $\mathbf{2}$ & $\mathbf{1}$ \\
\hline
\end{tabular}

5. ¿Volvería a participar en una actividad similar?, SI NO ¿Por qué?

6. Comentarios adicionales:

$-52-$

Construyendo Comunidades de Aprendizaje: Un Programa de Formación de Educadoras de niños y niñas de o a 6 años. Estrategias de vinculación entre la Familia y la Escuela. Rosa Nashiki, Roxanna Pastor, Miguel Pérez, Rocío Hernández, Leticia Lemus y Carla Ocón. 


\section{Cuestionario de evaluación de materiales impresos}

Nombre de la madre/padre:

Sala: Fecha de evaluación:

El presente instrumento tiene como finalidad evaluar la utilidad de los materiales y los contenidos de los mismos.

1. ¿Cómo se relaciona el tema con lo que le está ocurriendo a su hijo/a?

2. ¿Para qué le fue útil la información proporcionada?

3. ¿Qué tan útiles fueron las sugerencias que se le brindaron? ¿Por qué?

4. ¿Cómo el material elaborado le permitió acercarse a la educadora?

Comentarios adicionales: 


\section{Cuadernos \\ "Puentes para Crecer"}

El presente material pertenece a una colección de cuadernos producto del programa Puentes para Crecer. Los mismos representan experiencias y aprendizajes acerca del desarrollo, cuidado y bienestar de niños y niñas en la primera infancia. Cada cuaderno esta dirigido principalmente a usuarios como: niñas, niños, padres, madres y profesionales de la educación y la psicología.

Otras publicaciones de Puentes para Crecer:

Leo, escribo y utilizo los números en todos lados

¿Cómo educar a hijos e hijas sin lastimar?

¿Quién dijo que ser mamá o papá era fácil?

Hagamos juntos la tarea

Manual para promover el desarrollo de habilidades sociales en niños y niñas preescolares

CONSTRUYENDO COMUNIDADES DE APRENDIZAJE: UN PROGRAMA DE FORMACIÓN DE EDUCADORAS DE NIÑOS Y NIÑAS DE O A 6 AÑOS:

Implementación del Programa de Educación Preescolar (PEP-2004-SEP)

El desarrollo y aprendizaje infantil, y su observación

Manual de Implementación

Instrumento de Auto-Evaluación de Prácticas Educativas

El Desarrollo de Niños y Niñas Menores de Tres Años

Estas obras son de distribución gratuita, por los responsables de Puentes para Crecer en la Facultad de psicología, de la UNAM, Edificio E, Segundo Piso, Cubículo F.

CONSTRUYENDO COMUNIDADES DE APRENDIZAJE: UN PROGRAMA DE FORMACIÓN DE EDUCADORAS DE NIÑOS Y NIÑAS DE O A 6 AÑOS: ESTRATEGIAS DE VINCULACIÓN ENTRE LA FAMILIA Y LA ESCUELA

Fue desarrollado en el sub-proyecto: Programa de Formación de Educadoras

Sede: Estancias para el Bienestar y Desarrollo Infantil del ISSSTE

Responsable de elaboración del cuaderno: Mtra. Roxanna Pastor Fasquelle

Año de Impresión: 2011 Primera Edición

Este Material es el resultado del trabajo realizado en el programa Puentes para Crecer de la Facultad de Psicología de la UNAM, de la autora Mtra. Roxanna Pastor Fasquelle. Se prohíbe su reproducción total o parcial por cualquier medio sin la autorización escrita del titular de la obra. 
Cuadernos

\section{para Crecer}

y

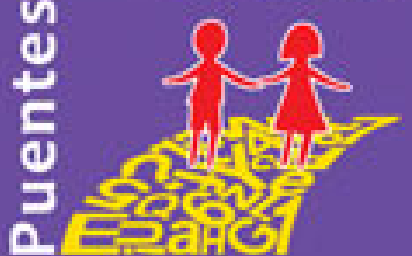

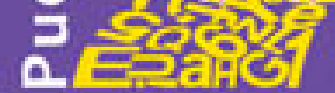

